This is a peer-reviewed, accepted author manuscript of the following article: Fleming, C. (2021). An investigation into the behaviour of selected boundary regime lubricants when cold forging steel under rolling-sliding conditions. Tribology International, 157, [106771]. https://doi.org/10.1016/j.triboint.2020.106771

\title{
An investigation into the behaviour of selected boundary regime lubricants when cold forging steel under rolling-sliding conditions
}

A study of PVD coatings, solid-in-liquid suspensions, and an ashless phosphate ester in oil at the upper die- workpiece interface when cold rotational rotary forging martensitic steel. The aim was to gain tribological insight for advanced near net-shape process development. The test method was a cylinder upsetting operation using an industrial-scale press, and lubricants were applied via in-process spraying. Forming cycle torque requirements were lowest when water-based suspensions were employed. However, there was a positive correlation between friction and homogeneity of through-thickness deformation, and oil-based dispersions generated superior surface roughness. A tribological synergism occurred using $\mathrm{MoS}_{2}$ microplatelets and an ashless phosphate ester mixed in mineral oil. This lubricant achieved higher quality surface finish and greater protection against adhesive wear than did each component dispersed separately.

\section{Introduction}

Severe tribological conditions are typical at the die-workpiece interface during metal forming operations. Consequently, to ensure high quality component surface finish and geometrical accuracy, along with optimal die life, matters of tribology must be given due consideration when designing a process. Despite this, to the best of the author's knowledge, there has been no prior publication of investigations into understanding and optimising the tribology of rotational rotary forging.

Cold rotational (alternatively rotating-die [1] or spin-nutation [2]) rotary forging is one of two general classes of cold rotary forging, with the other being cold orbital (alternatively rockingdie [1]) rotary forging. The former enables components to be produced with the greater 
precision, whilst a wider variety of geometries are possible with the latter [1]. Both are incremental techniques that enable high accuracy, near-net shape manufacture to be achieved at room temperature [3]. Parts may be fabricated by these methods that would otherwise have to be completely machined because of their shape or dimensions. A further advantage is that considerably lower forces are required than for conventional forging [4]. This is because only a small portion of the upper/lower die is in contact with the corresponding workpiece surface at any given instant. In recent years, increasingly sophisticated press control systems and finite element analysis (FEA) modelling have fuelled a revival in cold rotary forging research. This has enabled a trend away from traditional high-volume manufacture of circular components such as gears and bearing housings towards more specialised, high-value products. Methods under development include near net-shape manufacture of axisymmetric components with a $90^{\circ}$ bend flange from tubular preforms for the aerospace industry [5-7], and precision forging high-performance gear racks from long rod preforms [8].

The orbital class is currently the more prevalent of the two, in terms of both industrial usage and academic research. Published work with reference to matters of tribology is, however, scant. Investigations have tended to be FEA-based [9-11], and where different lubricants have been evaluated, friction was the sole criterion and the ring compression test was the method [12]. It may thus be inferred that die wear and workpiece surface finish are generally not concerns with cold orbital rotary forging. In contrast, die wear and workpiece surface finish can be key issues with cold rotational rotary forging. By way of example, during early-stage flange forming trials of the high-strength, martensitic steel Jethete M152, upper die pick-up was significant and die life was unacceptable. As described in Ref. [6], the as-formed surface was permeated by cracks and the near-surface microstructure was undesirable. The disparity in reported tribological issues may in part be because much conventional cold rotary forging manufacture is via deformation of a workpiece to fill a lower die mould, and for this purpose 
a precoat of dry-film $\mathrm{MoS}_{2}$ can suffice $[12,13]$. Dissimilar workpiece chemistries and mechanical properties may also be a factor. This notwithstanding, differences between the kinematics of the two kindred process types reveal that the upper die-workpiece tribological load is harsher for rotational rotary forging.

Orbital rotary forging features a typically conical upper die that is both inclined to and precesses about the axis of the workpiece, and a workpiece that does not rotate. With the most common variant (which is often simply referred to as orbital forging), the lower die translates the workpiece vertically and the upper die has neither rotational nor translational motion (Figure 1(a)). Tribological interactions at the upper die-workpiece interface are thus rolling with an element of slip introduced by workpiece surface expansion [9].

In rotational rotary forging, the upper die is likewise inclined and conical, and the lower die also holds the workpiece. In contrast, torque is applied to both dies to cause them to rotate about their own axis, neither die precesses about the axis of the other, and it is always the upper die that undergoes vertical translation (Figure 1(b)). For an interaction to be pure rolling, the tangential velocity of the top die and the workpiece must match at each point of contact. For this to occur, Equation (1) must be satisfied:

$$
r_{w} \omega_{l}=r_{u} \omega_{u}
$$

where, as illustrated in Figure 1(b), $r_{w}$ is a distance radially outward from the workpiece axis of rotation; $r_{u}$ is the upper die radius where it meets the workpiece at $r_{w} ; \omega_{1}$ is the angular velocity of the lower die; and $\omega_{u}$ is the angular velocity of the upper die. In practice, it is difficult to make this condition true. Consequently, upper die-workpiece tribological interactions are rolling-sliding with the sliding component augmented by deformation induced slip. 
The specific aim of this investigation was to overcome the aforedescribed pick-up and poor surface finish when cold rotational rotary forging Jethete M152 flanged test-pieces. The broader aim was to aid advancement of cold rotational rotary forging towards more highvalue manufacturing. That the purpose was process development as opposed to process optimisation was key in terms of the approach taken and the tribological insight sought. The focus was on small-batches and the fundamentals of lubricant behaviour, rather than longterm performance. A further consequence was that it was not possible to conduct experiments using a real geometry. As an alternative, a cylinder upsetting operation was chosen because this test method is widely used within cold orbital rotary forging research [14]. Despite the testpiece geometry and deformation modes differing from those associated with flange forming, contact geometries and kinematics can be made reasonably representative. Furthermore, it does not change that Jethete M152 is a challenging metal to cold forge [15]. Via this method, the performance of five lubricants coupled with each of two physical vapour deposition (PVD) coatings at the upper die-workpiece interface was assessed in terms of: (i) surface finish; (ii) process torque/friction; (iii) adhesive wear; and (iv) homogeneity of deformation.

\section{Experimental}

\subsection{Materials}

The upper die was machined from DC53 steel (Carrs Tool Steels Ltd., Tipton, UK) that was hardened at $1030{ }^{\circ} \mathrm{C}$ and tempered at $530{ }^{\circ} \mathrm{C}$ (Summitglow Ltd., Sheffield, UK). For the workpieces, cylinders were cut from a bar of Jethete M152 that had been hardened at $1050{ }^{\circ} \mathrm{C}$ and tempered at $650{ }^{\circ} \mathrm{C}$ (Tata Steel UK Ltd.). The final preform geometry was achieved via a lathe turning operation that resulted in a circular surface texture and an arithmetical mean 
surface roughness $(\mathrm{Ra})$ of $0.6 \mu \mathrm{m}$. The supplier stated compositions and hardness values of the die and workpiece alloys are shown in Table 1.

Table 1 Supplier stated wt.\% compositions and hardness values of the die and workpiece alloys.

\begin{tabular}{lllllllllllll} 
& Fe & $\mathrm{C}$ & $\mathrm{Si}$ & $\mathrm{Mn}$ & $\mathrm{P}$ & $\mathrm{Cr}$ & $\mathrm{Mo}$ & $\mathrm{Ni}$ & $\mathrm{Cu}$ & $\mathrm{N}$ & $\mathrm{V}$ & Hardness \\
\hline DC53 & $\mathrm{Bal}$ & 0.96 & 0.36 & 0.37 & - & 8.15 & 1.94 & - & - & - & 0.21 & 61.4 HRC \\
Jethete & $\mathrm{Bal}$ & 0.12 & 0.22 & 0.67 & 0.01 & 11.40 & 1.59 & 2.53 & 0.07 & 0.03 & 0.28 & $329 \mathrm{HBW} 30 / 1000$ \\
M152 & & & & & & & & & & & & \\
\hline
\end{tabular}

Two commercially sourced cathodic arc deposition PVD die coatings were evaluated: vanadium carbonitride (VCN) and titanium tungsten carbonitride (TiWCN). Hardness and fracture toughness were enhanced by nanoscale multilayer architectures [16, 17]. Addition of tungsten to the conventional ternary coating has been found to increase toughness without compromising hardness [18].

Details of the five lubricants that were tested are contained within Table 2. Four of these were as-received or diluted versions of commercial products; the fifth was synthesised by the author by combining a concentrated form of the $\mathrm{MoS}_{2}$ suspension with the phosphate ester in mineral oil. Adequate dispersion stability was assured by virtue of these lubricants having been formulated for industrial use. Stability between $\mathrm{MoS}_{2}$ and the phosphate ester was assessed by leaving 30 hours between the two sets of trials that involved this lubricant. As a precautionary measure, the reservoir was shaken by hand prior to application. Performance according to all metrics was invariant. This result is consistent with no chemical instabilities having been reported when tribological interactions between $\mathrm{MoS}_{2}$ nanoparticles and zinc dialkyl dithiophosphate (ZDDP) in polyalphaolefin (PAO) oil were investigated [19-21]. These findings can be understood from the extreme inertness of the $\mathrm{MoS}_{2}$ basal-plane surface and the absence of dangling bonds in the electron-filled shells of the terminal chalcogen atoms $[22,23]$. 
Table 2 Compositions of the lubricants that were evaluated. Particle sizes are given in terms of median diameter, D50, and are manufacturer provided nominal values.

\begin{tabular}{llllll}
\hline Solid-State Lubricant & & & \multicolumn{2}{c}{$\begin{array}{l}\text { Antiwear/ Extreme- } \\
\text { Pressure Additive }\end{array}$} & $\begin{array}{l}\text { Dispersion } \\
\text { Medium }\end{array}$ \\
\hline Identity & $\begin{array}{l}\text { Amount } \\
{[\%]}\end{array}$ & $\begin{array}{l}\text { Median Particle } \\
\text { Diameter (D50) } \\
{[\mu \mathrm{m}]}\end{array}$ & $\begin{array}{l}\text { Identity } \\
\text { Amount } \\
{[\%]}\end{array}$ & Identity \\
\hline Hexagonal boron nitride (h-BN) & 1.9 & 6.0 & None & $\mathrm{n} / \mathrm{a}$ & $\mathrm{H}_{2} \mathrm{O}$ \\
Zinc sulphide (ZnS) & 2.0 & 1.1 & None & $\mathrm{n} / \mathrm{a}$ & $\mathrm{H}_{2} \mathrm{O}$ \\
Molybdenum disulphide $\left(\mathrm{MoS}_{2}\right)$ & 2.2 & 1.0 & None & $\mathrm{n} / \mathrm{a}$ & Mineral Oil \\
None & $\mathrm{n} / \mathrm{a}$ & $\mathrm{n} / \mathrm{a}$ & $\begin{array}{l}\text { Ashless } \\
\text { phosphate } \\
\text { ester }\end{array}$ & 15 & Mineral Oil \\
Molybdenum disulphide & 2.2 & 1.0 & $\begin{array}{l}\text { Ashless } \\
\text { phosphate } \\
\text { ester }\end{array}$ & 11 & Mineral Oil \\
\hline
\end{tabular}

\subsection{Testing procedure}

The cylinder upsetting operation used to evaluate the lubricants and coatings has been detailed previously [2]. Trials were conducted using a bespoke, industrial-scale MJC RFN 200T-4 spin-nutation press, with a $170^{\circ}$ conical upper die and a flat lower die. Lubricant was applied using a customised minimum quantity lubricant (MQL) dispenser (Allube Ltd., Sheffield, UK). Continuous entrainment into the contact region was achieved by directing a high flow rate of atomised fluid onto the upper die forging face throughout the cycle. A brushing of mineral oil was applied to the base of the workpiece prior to insertion.

Two consecutive baseline runs involving an uncoated upper die and no lubricant were conducted first. Ten stand-alone forming cycles were then performed using the VCN and TiWCN coated upper dies and each of the lubricants. Following these, small-batch runs of seven parts in succession were conducted using the $\mathrm{ZnS}$ in $\mathrm{H}_{2} \mathrm{O}$ and $\mathrm{MoS}_{2} /$ phosphate ester in 
oil lubricants. The die was not cleaned between the runs comprising a set. Lastly, a forming cycle was performed with each of the coated dies in the absence of a lubricant.

Each forming cycle had a duration of approximately ten seconds. The process parameters are summarised in Table 3. Deviations in maximum forming loads and intra-cycle fluctuations of the rotational velocities were both indicative of natural variability. It is significant with respect to rolling-sliding that, without exception, the lower die velocity fluctuated about a different mean value than the upper die. Approximate temperatures during the forming cycle were measured using an AMETEK Land ARC Imager HF thermal camera. The maximum workpiece deformation temperature was in the region of $115^{\circ} \mathrm{C}$ (Figure $2(\mathrm{a})$ ). That the highest temperatures in Figure 2(a) are seen at the far-right hand side of the workpiece is a consequence of the contact being to the right of the workpiece axis and perpendicular to line of sight. The workpiece upper surface temperature exactly after forging was in the region of $110^{\circ} \mathrm{C}$ (Figure 2(b)).

Table 3 Parameters used in the cylinder upsetting operation.

\begin{tabular}{ll}
\hline Parameter & Value \\
\hline Initial diameter of the cylindrical workpiece & $50 \mathrm{~mm}$ \\
Initial height of the cylindrical workpiece & $20 \mathrm{~mm}$ \\
Height reduction & $45 \%$ \\
Target maximum forming load & $600 \mathrm{kN}$ \\
Actual maximum forming load & $585-629 \mathrm{kN}$ \\
Target upper die rotational velocity & $100 \mathrm{rpm}$ \\
Actual upper die rotational velocity & $97.9 \pm 0.6 \mathrm{rpm}$ \\
Target lower die rotational velocity & $100 \mathrm{rpm}$ \\
Actual lower die rotational velocity & $100.6 \pm 0.5 \mathrm{rpm}$
\end{tabular}


Upper die feed rate $\quad 80 \mathrm{~mm} \mathrm{~min}^{-1}$

Nutation angle $\quad 5^{\circ}$

\subsection{Analysis procedure}

The surface roughness of the coated upper dies was measured in the as-received condition and after the set of experiments was complete, using a Mitutoyo Surftest SJ-411 contact profilometer fitted with a $60^{\circ} / 2 \mu \mathrm{m}$ stylus tip.

The torque required to maintain upper die rotation exhibited a clear dependency on lubricant and coating identity. All other process parameters were effectively constant. It was therefore deemed valid to use torque as a comparative measure of frictional forces at the upper dieworkpiece interface. The data was extracted directly from the press control system as DAT files, and was plotted and analysed using OriginPro 2017.

Between runs, the upper die was taken out from the press and wiped with a soft cloth and degreaser to remove excess lubricant. The surface condition was evaluated visually using a Lynx EVO optical microscope. The die was then completely cleaned of adhered material using degreaser and a household plastic scouring pad.

Each formed workpiece was cleaned using degreaser and a soft brush. Surface features were evaluated qualitatively using a Leica DM12000M optical microscope and quantitatively with an Alicona InfiniteFocus G4 optical 3D surface measurement system. Roughness measurements were made using the Mitutoyo contact profilometer, and confirmatory measurements were made using the non-contact Alicona system. Preliminary assessments of transfer from die coating to workpiece were conducted using an FEI Quanta 650 fieldemission scanning electron microscope (SEM) equipped with Oxford Instruments Aztec 
energy dispersive spectroscopy (EDS) capability. Large-area elemental analysis was conducted on selected workpieces using a Bruker M4 Tornado micro x-ray fluorescence ( $\mu$ XRF) spectrometer at the Advanced Materials Manufacturing Centre, Warwick Manufacturing Group. Wire electro-discharge machining was used to bisect selected workpieces into half discs, which were then trimmed, polished, and mounted in conducting resin. This enabled the cross-section near-surface region to be imaged and analysed using the FEI SEM.

Upon completion of all trials, simultaneous imaging of the surface and near-surface region of the VCN coated die was performed by MCS Group (Edinburgh, UK). 'Deformation free' cross-sections were prepared using the proprietary Perfect Edge 3D ${ }^{\mathrm{TM}}$ ion beam method [24]. The analysis was conducted using a Zeiss Merlin field-emission SEM fitted with Oxford Instruments Aztec EDS capability.

\section{Results}

\subsection{Validation runs}

From the optical micrograph shown in Figure 3(a), it can clearly be seen that upsetting a single Jethete M152 cylinder using an uncoated die and no lubricant resulted in significant die pick-up. The detrimental effect that this had on both workpiece surface finish and friction was pronounced (Figure 3(b) and (c)).

\subsection{Upper die process torque}

\subsubsection{Torque-time plot features}

There are six features to each upper die torque-time plot that correspond to stages of the forming cycle; these are labelled in Figure 4 as follows: 
1. A sharp increase in torque occurred upon first contact between the upper die and the workpiece.

2. The rate of torque increase reduced momentarily, which is thought to have occurred when the workpiece assumed a stable position within the lower die.

3. Torque rose sharply again as the tool bit into the workpiece.

4. This stage comprises the forming region. Crucially, significant differences were evident across the range of coating/lubricant combinations.

5. Torque dropped rapidly as the die dwelled in the final forming position and the applied load was reduced.

6. A shoulder can be seen at the point that contact between the upper die and the workpiece ended. Thereafter, torque dropped sharply to the baseline value.

\subsubsection{Single forming cycles}

The upper die torque plots for each die coating/lubricant combination are shown in Figure 5. These have been presented so as to facilitate comparisons between (i) the two die coatings for each lubricant (Figure 5(a)-(f)), and (ii) the full range of lubricants for each of the two die coatings (Figure 5(g)-(h)). Total process torque, i.e. the area under the curve between Stage 1 and Stage 6, and the maximum torque required for each combination are listed in Table 4.

Table 4 Data extracted from the single-run upper die torque-time plots.

\begin{tabular}{|c|c|c|c|c|c|c|}
\hline \multirow{2}{*}{ Lubricant } & \multicolumn{2}{|c|}{$\begin{array}{c}\text { Total Process } \\
\text { Torque } \\
{[\mathrm{N} \mathrm{m} \mathrm{s}]}\end{array}$} & \multirow{2}{*}{$\begin{array}{l}\% \text { difference } \\
\text { in total } \\
\text { process torque } \\
\text { between die } \\
\text { coatings }\end{array}$} & \multicolumn{2}{|c|}{$\begin{array}{l}\text { Maximum Torque } \\
\qquad[\mathrm{N} \mathrm{m}]\end{array}$} & \multirow{2}{*}{$\begin{array}{l}\% \text { difference } \\
\text { in maximum } \\
\text { torque } \\
\text { between die } \\
\text { coatings }\end{array}$} \\
\hline & TiWCN & $\mathrm{VCN}$ & & TiWCN & $\mathrm{VCN}$ & \\
\hline None & 2033 & 1474 & 37.9 & 347 & 228 & 52.2 \\
\hline $\begin{array}{l}h-B N \text { in } \\
\mathrm{H}_{2} \mathrm{O}\end{array}$ & 1251 & 1138 & 9.9 & 182 & 163 & 11.7 \\
\hline
\end{tabular}




\begin{tabular}{lcccccc}
$\begin{array}{l}\mathrm{ZnS} \text { in } \\
\mathrm{H}_{2} \mathrm{O}\end{array}$ & 1291 & 1168 & 10.5 & 172 & 156 & 10.3 \\
$\begin{array}{l}\mathrm{MoS} \\
\text { oil in }\end{array}$ & 1782 & 1382 & 28.9 & 300 & 214 & 40.2 \\
$\begin{array}{l}\text { Phosphate } \\
\text { ester in oil }\end{array}$ & 1770 & 1575 & 12.4 & 292 & 259 & 12.7 \\
$\begin{array}{l}\text { MoS } \text { and } \\
\text { phosphate } \\
\text { ester in oil }\end{array}$ & 1642 & 1590 & 3.3 & 267 & 265 & 0.8 \\
\hline
\end{tabular}

From inspection of the plots, the forming region, i.e. Stage 4, was one of three types. For the runs that involved either no lubricant or a mineral oil-based lubricant, the required torque became greater over the whole of this region, and approximately midway there was a pronounced increase in the rate at which this occurred (Figure 5(a) and (d)-(f)). For the two water-based lubricants, there was no mid-cycle increase. For the h-BN suspension, after an initially increasing rate there was a sharp decrease to the extent that the slope became negative (Figure 5(b)). This downward trend was momentarily bucked at the end of the forming region by a small peak. For the $\mathrm{ZnS}$ suspension, torque either increased at steady rate or remained reasonably consistent over the entire course of the forming region (Figure 5(c)).

In the absence of a lubricant, the torque required for the TiWCN coated die was significantly greater than for the VCN coated die at every point in the forming region (Figure 5(a)). Whilst the total and maximum torque values continued to be higher for the TiWCN coated die in every pair of lubricated cycles, a clear effect of all lubricants was to reduce the extent of the differences. In terms of establishing parity between the two PVD coatings, $\mathrm{MoS}_{2}$ in mineral oil was the worst performer, and $\mathrm{MoS}_{2}$ combined with the phosphate ester in mineral oil was the best performer; both by significant margins. 
In order of increasing magnitude, the percentage difference between the integrated areas of each of the lubricated TiWCN forming cycle plots and the unlubricated cycle are: h-BN in $\mathrm{H}_{2} \mathrm{O}(61.5 \%) \approx \mathrm{ZnS}$ in $\mathrm{H}_{2} \mathrm{O}(63.5 \%)<\mathrm{MoS}_{2}$ and phosphate ester in mineral oil $(80.8 \%)<$ phosphate ester in mineral oil $(87.1 \%) \approx \mathrm{MoS}_{2}$ in mineral oil $(87.7 \%)$. For the VCN plots, these are: h-BN in $\mathrm{H}_{2} \mathrm{O}(77.2 \%) \approx \mathrm{ZnS}$ in $\mathrm{H}_{2} \mathrm{O}(79.2 \%)<\mathrm{MoS}_{2}$ in mineral oil $(93.8 \%)<$ phosphate ester in mineral oil $(106.9 \%) \approx \mathrm{MoS}_{2}$ and phosphate ester in mineral oil $(107.9 \%)$.

\subsubsection{Small-batch runs}

The upper die torque-time plots from the $\mathrm{ZnS}$ in $\mathrm{H}_{2} \mathrm{O}$ small-batch runs are shown in Figure 6(a) and (b). Data extracted from these plots is contained within Table 5. The total process torque for the first cycle in each sequence was slightly lower than for the corresponding single cycle, which may be taken as a measure of the variance associated with this lubricant. The second cycles required significantly less torque than the first, 9.8\% (TiWCN) and 7.9\% (VCN), and the difference between the two die coatings was $4.5 \%$. From the third cycle onwards, torque stabilised at an equivalent value for both die coatings; TiWCN: $1076 \pm 7 \mathrm{~N}$ $\mathrm{m} \mathrm{s}( \pm 0.3 \%)$, and VCN: $1072 \pm 3 \mathrm{~N} \mathrm{~m} \mathrm{~s}( \pm 0.3 \%)$. Subsequent to stabilisation, the mean difference between die coatings for corresponding positions in the sequence was $0.8 \pm 0.7 \%$. It is notable that for these cycles, the torque profile over the forming region was essentially flat.

It is clear from Figure 6(c) and (d) and Table 6 that the torque-time plots for all sixteen forming cycles conducted using the TiWCN and VCN coated dies and the $\mathrm{MoS}_{2} /$ phosphate ester in mineral oil lubricant exhibited a high degree of congruency. The mean total process torque for all TiWCN runs was $1635 \pm 25 \mathrm{~N} \mathrm{~m} \mathrm{~s}( \pm 1.5 \%)$, and for VCN it was $1609 \pm 16 \mathrm{~N}$ $\mathrm{m} \mathrm{s}( \pm 1.0 \%)$. The mean difference between die coatings for each corresponding run was 2.1 $\pm 1.4 \%$. 
Table 5 Data extracted from the upper die torque-time plots from the $\mathrm{ZnS}$ in $\mathrm{H}_{2} \mathrm{O}$ small-batch runs.

\begin{tabular}{cccccc}
\hline \multirow{2}{*}{$\begin{array}{c}\text { Position } \\
\text { in run }\end{array}$} & $\begin{array}{c}\text { Total } \\
\text { Process } \\
\text { Torque } \\
{[\mathrm{N} \mathrm{m} \mathrm{s}]}\end{array}$ & $\begin{array}{c}\text { TiWCN } \\
\text { difference } \\
\text { cf. single- } \\
\text { run }\end{array}$ & $\begin{array}{c}\text { Total } \\
\text { Process } \\
\text { Torque } \\
{[\mathrm{N} \mathrm{m} \mathrm{s}]}\end{array}$ & $\begin{array}{c}\text { VCN } \\
\text { difference } \\
\text { cf. single- } \\
\text { run }\end{array}$ & $\begin{array}{c}\text { \% difference } \\
\text { between die } \\
\text { coatings for } \\
\text { corresponding } \\
\text { runs }\end{array}$ \\
\hline 1 & 1221 & -5.4 & 1145 & -2.0 & 6.6 \\
2 & 1101 & -14.7 & 1054 & -9.8 & 4.5 \\
3 & 1071 & -17.0 & 1076 & -7.9 & 0.5 \\
4 & 1074 & -16.8 & 1069 & -8.5 & 0.5 \\
5 & 1090 & -15.6 & 1067 & -8.6 & 2.2 \\
6 & 1070 & -17.1 & 1074 & -8.0 & 0.4 \\
7 & 1076 & -16.7 & 1072 & -8.2 & 0.4 \\
\hline
\end{tabular}

Table 6 Data extracted from the upper die torque-time plots from the $\mathrm{MoS}_{2}$ and phosphate ester in mineral oil small-batch runs.

\begin{tabular}{|c|c|c|c|c|c|}
\hline \multirow[b]{2}{*}{$\begin{array}{l}\text { Position } \\
\text { in run }\end{array}$} & \multicolumn{2}{|c|}{ TiWCN } & \multicolumn{2}{|c|}{$\mathrm{VCN}$} & \multirow{2}{*}{$\begin{array}{l}\text { \% difference } \\
\text { between die } \\
\text { coatings for } \\
\text { corresponding } \\
\text { runs }\end{array}$} \\
\hline & $\begin{array}{l}\text { Total } \\
\text { Process } \\
\text { Torque } \\
{[\mathrm{N} \mathrm{m} \mathrm{s}]}\end{array}$ & $\begin{array}{c}\% \\
\text { difference } \\
\text { cf. single- } \\
\text { run }\end{array}$ & $\begin{array}{c}\text { Total } \\
\text { Process } \\
\text { Torque } \\
{[\mathrm{N} \mathrm{m} \mathrm{s}]}\end{array}$ & $\begin{array}{c}\% \\
\text { difference } \\
\text { cf. single- } \\
\text { run }\end{array}$ & \\
\hline 1 & 1644 & 0.1 & 1598 & 0.5 & 2.9 \\
\hline 2 & 1640 & -0.1 & 1627 & 2.3 & 0.8 \\
\hline 3 & 1599 & -2.2 & 1595 & 0.3 & 0.3 \\
\hline 4 & 1629 & -0.3 & 1594 & 0.3 & 2.2 \\
\hline 5 & 1656 & 0.8 & 1598 & 0.5 & 3.6 \\
\hline 6 & 1591 & -2.6 & 1610 & 1.3 & 0.2 \\
\hline 7 & 1661 & 1.6 & 1603 & 0.8 & 3.6 \\
\hline
\end{tabular}




\subsection{Die Surface Condition}

\subsubsection{Pick-up and adhered lubricant}

Optical micrographs from the apex region of the VCN coated die after each single cycle trial are shown in Fig. 7(a) - (f). Notable die-bound material was observed when either no lubricant, h-BN in $\mathrm{H}_{2} \mathrm{O}$, or phosphate ester in mineral oil was used. In contrast, only slight material was evident after the $\mathrm{ZnS}$ in $\mathrm{H}_{2} \mathrm{O}$ run, and coverage was barely discernible, if at all, with $\mathrm{MoS}_{2}$ in mineral oil and $\mathrm{MoS}_{2} /$ phosphate ester in mineral oil.

Since no lubricant was present for the unlubricated run, this material must have originated from the workpiece. Since the phosphate ester in mineral oil did not contain solid-state lubricant particles, the adhered material must have also originated from the workpiece. The adhered material in both cases had a lustrous appearance.

When h-BN in $\mathrm{H}_{2} \mathrm{O}$ was used, matt material was distributed in a spiral pattern across the main body of the forging face, and patches of lustrous material were present at the apex. Disparate appearances and distribution patterns indicate different sources, and it is reasoned that the matt material was lubricant particles, and that which exhibited sheen was transfer from the workpiece. The presence of the latter is consistent with research that found h-BN films to be prone to localised breakthroughs when subjected to high loads [25]. The matt appearance of adhered material after using all other solid-state particle containing lubricants is indicative of having been lubricant particles.

Fig. 7(g) and (h) show that more material was adhered after the runs of seven consecutive parts than after the corresponding single cycles. In the case of $\mathrm{ZnS}$ in $\mathrm{H}_{2} \mathrm{O}$, this material was across the main body of the forging face and of equivalent appearance to the lubricant film 
after the h-BN in $\mathrm{H}_{2} \mathrm{O}$ forming cycle. For $\mathrm{MoS}_{2} /$ phosphate ester in mineral oil, a single patch, approximately $1 \mathrm{~mm}$ in diameter, of distinctly matt material was located at the apex.

\subsubsection{Die coating durability}

The virgin coated dies had Ra values of $64 \pm 9 \mathrm{~nm}(\mathrm{VCN})$ and $99 \pm 13 \mathrm{~nm}(\mathrm{TiWCN})$. The forming cycles did not result in any change in these values.

Observable die coating wear over the course of the lubricated runs was solely in the form of roundish depressions with diameters of the order of tens of micrometres. These can be seen in Figure 7 to have become progressively more prevalent. Both coatings were affected similarly. Combined surface and cross-section SEM/EDS analysis of the post-trial VCN coating revealed these features to be associated with spherical vanadium inclusions that predominantly had diameters $<1 \mu \mathrm{m}$ and were no larger than $2 \mu \mathrm{m}$ (Figure 8 ). Such macroparticles are a well-recognised drawback of arc-PVD and result from the ejection of metal droplets during the target evaporation process [26]. The spherical morphology is typical and is a consequence of solidifying prior to arriving on the substrate surface [27]. It is thought that a further consequence of pre-impact solidification was the cavity that encompassed the lower region of each macro-particle.

Based on these and other surface features that are highlighted in Figure 8, the following is proposed to explain the observed depressions. Due to the voids, the coating directly above the droplets was unsupported, resulting in the formation of sinkholes upon loaded contact with workpiece. With subsequent contact events, cracks initiated and propagated sub-surface. These led to wear particles being released from between individual sinkholes, and the creation of depressions that were an order of magnitude wider than the macro-particles. This 
process differs from wear mechanisms based on droplet collapse or ejection that have been reported during ball-on-disc tests [28, 29].

Dark patches, some with lengths $>1 \mathrm{~cm}$, appeared on the forging face after the unlubricated runs only, and to a similar extent with both PVD coatings (Figure 9). These features were unaffected by rubbing with fine grit silicon carbide paper and were most probably regions where the coatings had sustained damage.

\subsubsection{Die coating transfer}

SEM and EDS analysis of the upper surface of formed workpieces found that adhesive wear occurred with each of the PVD coatings. This wear took the form of sporadic titanium- or vanadium-rich transfer patches that appeared dark in secondary electron images (Figure 10). Titanium patches were typically $<50 \mu \mathrm{m}$ and up to $300 \mu \mathrm{m}$ in length; vanadium patches were all $<20 \mu \mathrm{m}$. This suggests that TiWCN was more susceptible to transfer than VCN.

To investigate potential synergism between $\mathrm{MoS}_{2}$ micro-platelets and the phosphate ester, the extent of transfer that occurred when these were dispersed alone and together in oil was quantified using $\mu$-XRF. Because the workpiece material contained vanadium and not titanium, only workpieces formed using the TiWCN coated die were analysed in this manner. $\mu$-XRF permits large measurement areas at the sacrifice of surface sensitivity. Accordingly, much of the component upper surface was scanned, and detected levels of titanium were on the cusp of the instrument limit of detection. Therefore, in order to mitigate instrument variability, samples were run in two batches.

One batch comprised: (i) the single-run $\mathrm{MoS}_{2} /$ phosphate ester in mineral oil sample, (ii) sample \#5 (selected at random) from the $\mathrm{MoS}_{2} /$ phosphate ester in mineral oil small-batch run, and (iii) a sample blank, i.e. Jethete M152 that had not come into contact with any source of titanium. 
The titanium signal from all three samples was equivalent, at $0.0053 \mathrm{wt} . \%, 0.0053 \mathrm{wt} . \%$ and 0.0055 wt. $\%$, respectively. Thus, transfer to (i) and (ii), with at least one patch having been observed on each, was so slight that it was indistinguishable from noise.

For the second batch, the lowest level of titanium was detected at the surface of a sample formed using $\mathrm{MoS}_{2} /$ phosphate ester in mineral oil. The amount was $18 \%$ greater for the phosphate ester in mineral oil sample, and $48 \%$ greater for the $\mathrm{MoS}_{2}$ in mineral oil sample. Another way to view this data is in terms of the number of data points in the element map of greater intensity than that of the maximum generated in the sample blank. Out of over one million data points collected, using a $20 \mu \mathrm{m}$ spot size with a $35 \mu \mathrm{m}$ separation distance, 7 were more intense than the background level for the $\mathrm{MoS}_{2} /$ phosphate ester lubricant, 25 for phosphate ester alone and 159 for $\mathrm{MoS}_{2}$ alone. By this method, the extremely low level of transfer in all three cases and the existence of a trend are clear.

\subsection{Workpiece surface finish}

\subsubsection{Top-down analysis}

Photographs and micrographs of workpieces formed using each of the five lubricants are shown in Figure 11 and 12, respectively. There was a clear dependency on the identity of the lubricant and no apparent dependency on the identity of the die coating.

In terms of macroscopic appearance, the workpieces formed using h-BN in $\mathrm{H}_{2} \mathrm{O}$ had a polished but not reflective appearance; $\mathrm{ZnS}$ in $\mathrm{H}_{2} \mathrm{O}$ were slightly reflective; $\mathrm{MoS}_{2}$ in mineral oil were highly reflective but flawed areas were significant; phosphate ester in mineral oil and $\mathrm{MoS}_{2} /$ phosphate ester in mineral oil were highly reflective and flawed areas were minimal.

Optical microscope-based observations corresponded with those on the macroscale. Irregularly shaped pit-like features up to $5 \mu \mathrm{m}$ deep were widespread across the surface of 
workpieces formed using h- $\mathrm{BN}$ in $\mathrm{H}_{2} \mathrm{O}$, and to a lesser extent for $\mathrm{ZnS}$ in $\mathrm{H}_{2} \mathrm{O}$. No such indentations were observed at the surface of the workpieces formed during the $\mathrm{MoS}_{2}$ in mineral oil, phosphate ester in mineral oil and the $\mathrm{MoS}_{2} /$ phosphate ester in mineral oil trials. Elongated patterns of dark marks were clear on the components formed using $\mathrm{MoS}_{2}$ in mineral oil but not on those using the other oil-based lubricants. That similar appearing marks occurred and to a much greater extent when no lubricant was employed (Fig. 12(f)) suggests that they were a consequence of direct contact between the workpiece and the die. The components from the unlubricated runs additionally exhibited grooves that were several hundred micrometres in length (Figure 13(a)). Ubiquitous across the surface of all samples were arcs that were predominantly $<0.1 \mu \mathrm{m}$ deep and orientated with the centre towards the centre of the part. These may have been artefacts of the circular surface texture introduced by the preform manufacture turning operation.

The Ra achieved with each lubricant/ die coating combination is given in Table 7. No direction dependence was discernible, and each presented value is the mean of ten measurements. The Ra of every workpiece that was formed with the VCN coated die was lower than that of the corresponding workpiece formed with the TiWCN coated die. This is consistent with the TiWCN coated die having been rougher than the VCN coated die.

For each of the die coatings, the trend across the range of lubricants was the same. The highest surface roughness occurred when h-BN in $\mathrm{H}_{2} \mathrm{O}$ was used, and this was approximately three times that of the workpiece formed using $\mathrm{ZnS}$ in $\mathrm{H}_{2} \mathrm{O}$. The roughness measurements for those formed using $\mathrm{MoS}_{2}$ in mineral oil, phosphate ester in mineral oil and $\mathrm{MoS}_{2} /$ phosphate ester in mineral oil were equivalent, and the lowest by a factor of approximately 2.5 . The surface roughness of all parts formed during the small-batch runs was within one standard deviation of the others comprising the run and of the corresponding single cycle part. 
Table 7 Arithmetical mean surface roughness of the components formed using each PVD coating and lubricant combination.

\begin{tabular}{lrr}
\hline \multirow{2}{*}{ Lubricant } & \multicolumn{2}{c}{ Ra [nm] } \\
& TiWCN & VCN \\
\hline h-BN in $\mathrm{H}_{2} \mathrm{O}$ & $262 \pm 38$ & $172 \pm 23$ \\
$\mathrm{ZnS}$ in $\mathrm{H}_{2} \mathrm{O}$ & $85 \pm 8$ & $63 \pm 12$ \\
$\mathrm{MoS}_{2}$ in mineral oil & $39 \pm 6$ & $27 \pm 5$ \\
Phosphate ester in mineral oil & $35 \pm 5$ & $24 \pm 3$ \\
$\mathrm{MoS}_{2} /$ phosphate ester in mineral oil & $38 \pm 4$ & $25 \pm 5$ \\
\hline
\end{tabular}

\subsubsection{Cross-section analysis}

The workpieces formed using no lubricant exhibited depressed regions with widths and depths of the order of tens of micrometres (Figure 13(b)). The peripheries tended to be raised above the surface plane, which is indicative of material having been displaced sideways as a groove was ploughed. These features thus correspond to the grooves observed in the topdown analysis. Cross-section analysis also revealed the presence of surface-initiated cracks that had propagated in directions almost parallel to the surface (Figure 13(c)). These resembled crack patterns that culminate in the release of wear particles during unlubricated sliding [30]. Consequently, it is possible that the grooves formed via wear particle abrasion.

No such sub-surface crack patterns were evident with the workpieces formed using lubricants. The workpiece from the $\mathrm{ZnS}$ in $\mathrm{H}_{2} \mathrm{O}$ run had an extensively uneven surface with depressions that had a maximum depth of approximately $5 \mu \mathrm{m}$ (Figure 14(a)). The workpiece formed using $\mathrm{MoS}_{2}$ in mineral oil exhibited a generally very even surface except for occasional depressions that were similarly deep (Figure 14(b) and (c)). That these features were not evident from the top-down analysis is a gauge of how sporadic they were. The 
component from the phosphate ester in mineral oil trial had a very even surface and no depressions. In spite of this, the surface was not flawless because also apparent from the cross-section analysis but not from the top-down analysis were small off-vertical tears that were up to $6 \mu \mathrm{m}$ deep and $11 \mu \mathrm{m}$ long (Figure 14(d)). The workpiece formed using $\mathrm{MoS}_{2} /$ phosphate ester in mineral oil displayed a very even surface with no depressions and no off-vertical tears.

\subsection{Homogeneity of deformation}

The "mushroom effect" is a well-known geometric defect that can occur when cylinder upsetting via cold orbital rotary forging [30]. This defect is so titled because the formed part has an obvious inverted mushroom head shape that stems from the diameter of the upper surface being significantly greater than that of the lower surface [31]. The geometry of the components formed in this study shows that this defect also occurs when cylinder upsetting via cold rotational rotary forging (Figure 15(a)). Albeit the effect manifested slightly differently in that the maximum workpiece diameter occurred at a height slightly below the upper surface.

In a slight modification to the method used by Han and Hua [10], the extent of the "mushroom effect" is quantified here using Equation 2:

$$
\Delta \varepsilon_{U L}=\frac{D_{U}-D_{L}}{D_{0}} \times 100 \%
$$

Where $\mathrm{D}_{0}$ is the initial diameter of workpiece, and $\mathrm{D}_{\mathrm{U}}$ and $\mathrm{D}_{\mathrm{L}}$ are the diameters of the upper and lower surfaces, respectively, of the formed workpiece (the slight modification is the use of the upper surface diameter rather than the maximum diameter in order to facilitate measurement). As the "mushroom effect" is essentially a strain difference between the upper and lower interfaces, in this present work this value is denoted by $\Delta \varepsilon_{\mathrm{UL}}$. 
Figure 15(b) shows a plot of $\Delta \varepsilon_{\mathrm{UL}}$ against upper die total process torque for all workpieces formed in this study. A trend of increasing homogeneity of through-thickness deformation with increasing torque is clear. The basis of this phenomenon can be appreciated from the inset. A trend of increasing lower surface diameter with increasing torque contrasts with the absence of any discernible correlation between upper surface diameter and torque.

\section{Discussion}

A cylinder upsetting operation conducted using a full-scale industrial press showed that cold rotational rotary forging a tool steel die directly against a martensitic steel can result in extensive die pick-up, considerable increases in friction with subsequent parts, and poor workpiece surface finish. A TiWCN or VCN PVD die coating significantly reduced the extent of pick-up, but surface finish remained unacceptable and macroscale coating damage occurred after a single forming cycle. In-process spraying of a lubricant enabled further improvements, the nature and extent of which were strongly dependent on the active component and the carrier liquid. Before proceeding with an attempt to rationalise these findings, a brief description of current accepted modes of action of each of the lubricant types will be given. The purpose of this is to aid reader comprehension, if required, of what follows.

The boundary lubrication functionality of particles dispersed in liquid arises when the solid phase transfers out of suspension under contact pressure, whereupon the particles: (i) buildup into a continuous tribofilm [32]; (ii) fill the valleys of the contacting surfaces [33, 34]; and/or (iii) become trapped between asperity junctions [33, 34]. Both h-BN and $\mathrm{MoS}_{2}$ have been well studied. Each has a lamellar crystal structure in which strong covalent intra-plane bonding contrasts with weak van der Waals inter-plane interactions. Consequently, particles are low shear along the basal plane direction and load supporting along the direction of the 
principal axis. This, coupled with the tendency of the plate-like particles to align with the sliding direction, is what endows these materials with beneficial tribological properties. In contrast, $\mathrm{ZnS}$ does not adopt a lamellar crystal structure and, despite being well recognised as a lubricant additive [35], studies concerning mechanisms of action are scant. This notwithstanding, $\mathrm{ZnS}$ can exist in several crystal structures and friction and wear reducing properties are said to stem from the close-packed hexagonal polymorph being of low shear strength [36].

Ashless phosphate esters are variously described as being antiwear (AW) or extreme-pressure (EP) additives. This could be as much to do with a functionality that fulfils the criteria of both, as the distinction between the two not being clear-cut [37]. They function in ferrous systems via adsorption, decomposition, and reaction to form mechanically strong iron polyphosphate films [38]. By this mechanism, these molecules can both augment the wear resistance of natural protective oxide layers and pacify nascent surface where these layers are compromised.

This first aspect of lubricant performance to be discussed is workpiece surface finish. Unconstrained metal surfaces tend to roughen when undergoing plastic deformation [39]. In the presence of a die and a very thin lubricant film, the workpiece surface will conform to that of the forging face and an equivalent roughness can be obtained [40]. With a thicker lubricant film, direct contacts between opposing asperities are impeded to the detriment of workpiece smoothing. That the Ra of all components formed using the two $\mathrm{MoS}_{2}$ containing lubricants was identical to when the lubricant without a solid phase was employed, reveals that the micro-platelets gave rise to extremely thin, possibly even single-particle, barriers at junctions. It thus follows that continuous particle-based tribofilms did not form on either the workpieces or the dies. It also follows that $\mathrm{MoS}_{2}$ did not occupy the regions between die 
asperities. This can be rationalised by considering that for valley filling to occur, the condition D50 $<4$ Ra must be met, where Ra refers to the roughness of the harder surface [33]. Clearly, $1 \mu \mathrm{m} \nless 0.256 \mu \mathrm{m}(\mathrm{VCN}) / 0.396 \mu \mathrm{m}$ (TiWCN). It is striking that the Ra of all components formed using an oil-based lubricant was considerably lower (by a factor of up to approximately three) than that of the corresponding die. In contrast, the surfaces obtained using the water-based dispersions were either similar or several times rougher. This disparity is attributed to the $>100{ }^{\circ} \mathrm{C}$ workpiece upper surface temperature having caused aqueous carrier fluid to vaporise, with resultant deposition of solid-state films. That the Ra of all components from each of the $\mathrm{ZnS}$ in $\mathrm{H} 2 \mathrm{O}$ small-batch runs was invariant despite intra-run increases of die-bound lubricant, indicates that this effect was dominated by the workpiece coverage.

The workpieces formed using solid-state particles only in dispersion had surfaces that were either peppered with or sporadically interrupted by shallow depressions. That this was not the case when the particle-free phosphate ester in oil was used indicates that the micro-particles either abraded or imprinted the workpiece. The abrasive nature of $\mathrm{MoS}_{2}$ and h-BN has been reported previously [33, 41], and abrasiveness has been found to increase with particle size [34]. This effect has been explained for $\mathrm{MoS}_{2}$ as being a consequence of the highly anisotropic crystal structure. Although the mean hardness of $\mathrm{MoS}_{2}$ is only about $1-1.5$ on the Mohs scale, the crystallite edges can be as high as 8 Mohs [42]. In contrast, ZnS crystallites are isotropic and so the hardness of $\approx 3.5$ Mohs is directionally independent. Consideration of the relative extent of these surface imperfections with lubricant identity reveals that, as with roughness, the most critical factor was whether the carrier liquid vaporised. The effect of this was so great that the surface quality obtained with $\mathrm{ZnS}$ was considerably worse than that obtained with $\mathrm{MoS}_{2}$, despite the particles having a significantly lower maximum hardness and an equivalent D50. When $\mathrm{MoS}_{2}$ was combined with the 
phosphate ester, these depressions did not occur. Furthermore, the small off-vertical tears that were observed at the surface of components formed using the phosphate ester alone in oil did not occur when $\mathrm{MoS}_{2}$ was also present in dispersion. These findings are suggestive of a tribological synergism.

The forming cycles conducted using the water-based lubricants required less upper die torque, by a considerable margin, than all the oil-based lubricants. Carrier liquid vaporisation to leave a solid-state film has been found by other researchers to have a similar friction reducing effect [43], so as with other results presented here, this is attributed to being the cause. That torque reduced with consecutive $\mathrm{ZnS}$ in $\mathrm{H}_{2} \mathrm{O}$ runs when there was no intermediate die cleaning shows that accumulation of lubricant particles on the die resulted in lower friction. This effect has been previously observed with a laboratory-scale sliding tribometer [44]. It can thus be inferred from torque having been invariant during the smallbatch $\mathrm{MoS}_{2} /$ phosphate ester runs that $\mathrm{MoS}_{2}$ was not effective at transferring out of oil and onto the dies.

Although frictional forces were comparatively high when the oil-based lubricants were used, no detrimental effects were detected. High friction can shorten die life; however, this is not the sole contributor, and die wear can be a complex interplay of many phenomena. This was in evidence here by the VCN die coating having sustained macroscale damage during a single unlubricated run, yet not after nine cycles involving lubricants that required greater torque. Metal forming tribological optimisation can be more a matter of controlling friction than simply reducing friction [45]. Indeed, results presented here indicate that for cold rotational rotary forging, higher friction at the upper die interface is beneficial to the homogeneity of through-thickness deformation. This seemingly increased metal flow at the lower interface without affecting the extent of flow at the upper interface. Matters are further obfuscated 
when it is considered that these findings are opposite to those from an FEA investigation of an analogous cold orbital rotary forging cylinder upsetting operation [10]. The authors attributed the "mushroom effect" to the contact area between the upper die and the workpiece being smaller than that between the lower die and the workpiece. Forming stresses at the upper region of the workpiece are consequently larger than at the lower region, and so a deformation gradient exists. It was found that lower friction at either or both die-workpiece interfaces would reduce the "mushroom effect".

Out of all the pairs of corresponding forming cycles, the most disparate torque-time plots by far were from the unlubricated runs. Furthermore, all the TiWCN runs required greater torque than those that involved the VCN die. It therefore seems reasonable to propose that the degree of equivalence between the TiWCN and VCN plots when a lubricant was employed be used as an indicator of direct contact between die and workpiece. In other words, in the hypothetical event of a pair of plots being identical, it is probable that the friction generating processes were identical. This would suggest that the lubricant used gave rise to complete separation at the die-workpiece interface. After three forming cycles with no intermediate die cleaning, the $\mathrm{ZnS}$ in $\mathrm{H}_{2} \mathrm{O}$ torque-time plots converged to a remarkable and consistent level of equivalence. The conditioning cycles were necessary for a lubricant film of sufficient thickness to amass on the die. A high degree of equivalence occurred with $\mathrm{MoS}_{2}$ and phosphate ester in mineral oil, without the requirement of conditioning cycles and without evidence of lubricant particle accumulation except at the very apex of the die.

That $\mathrm{MoS}_{2}$ and phosphate ester in mineral oil reproducibly generated a virtually complete interfacial barrier is supported by the results of the $\mu$-XRF analysis. For a given die coating, the extent of transfer to the workpiece will be a function of the extent of direct contact. Transfer was equally negligible after the standalone forming cycle as it was after cycles 
comprising a small-batch run. Furthermore, and consistent with torque plot differences, transfer was greater for $\mathrm{MoS}_{2}$ alone in oil than phosphate ester alone in oil, and when both were mixed, it reduced to a level that was lower than with each. Concerning transfer in the opposite direction, the addition of $\mathrm{MoS}_{2}$ protected against die pick-up so pronounced when the phosphate ester was used alone that it was clear to the naked eye. This presumably occurred where conditions at the workpiece asperities were insufficient to surmount the AW/EP reaction energy-threshold.

These adhesive wear results, along with the torque plot equivalencies and findings from the workpiece near-surface cross section analysis, suggest a tribological synergism between micro-MoS 2 and ashless phosphate esters. To the best of the author's knowledge, such a relationship has not previously been reported; consequently, comparable prior studies from which to derive an explanatory theory are scant. During rolling-sliding mini traction machine tests conducted in a bath of $5 \% \mathrm{MoS}_{2}$ nanotubes and $2 \% \mathrm{ZDDP}$ in PAO oil at $100{ }^{\circ} \mathrm{C}, \mathrm{ZDDP}$ tribofilms formed in contact with the steel disc and patches of $\mathrm{MoS}_{2}$ lamellae were exfoliated on top [20]. Similar results were reported for reciprocating pin-on-flat tests involving $\mathrm{WS}_{2}$ and ZDDP in PAO, also at $100{ }^{\circ} \mathrm{C}$ [46]. In contrast to rotational rotary forging conditions, however, the test durations were several hours, and the discs underwent no plastic deformation other than any associated with wear track formation. Furthermore, although ZDDP protective films similarly comprise metal polyphosphates, the formation mechanisms and nature are markedly different from AW/EP films generated by ashless phosphate esters [38].

It is clear from results that $\mathrm{MoS}_{2}$ particles did not prevent the ashless phosphate ester from operating. This may be expected because $\mathrm{MoS}_{2}$ is oleophilic, and so when in a mixture with polar molecules, the latter tend to compete effectively and adsorb more strongly [47]. 
Consequently, the synergism may have simply resulted from a combination of AW/EP additive pacifying nascent workpiece via reaction and particles functioning as transient barriers when caught between asperity junctions $[33,34]$. The apparent virtual completeness would thus have followed from each lubricant component serving as a second line of defence for the other. In line with this, it is conceivable that an underlying reacted layer could protect the workpiece from lubricant particle abrasion, and that atop platelets could improve flow to prevent workpiece tearing during deformation. Turning attention to torque data, when the die coating was TiWCN, $\mathrm{MoS}_{2}$ in mineral oil reduced the total requirement (compared to the unlubricated run) by $12 \%$; phosphate ester in mineral oil reduced it by $13 \%$; and $\mathrm{MoS}_{2}$ and phosphate ester in mineral oil reduced it by 19\%. A clear synergistic effect. In contrast, with the $\mathrm{VCN}$ coated die, whilst $\mathrm{MoS}_{2}$ in mineral oil reduced it by $6 \%$, phosphate ester in mineral oil increased it by $7 \%$, and with a $+1 \%$ change, the addition of $\mathrm{MoS}_{2}$ to the phosphate ester dispersion had no appreciable effect. This may be rationalised by considering that when an AW/EP film is sheared, as will inevitably occur throughout a metal forming operation, friction losses result by virtue of it being tough [48]. In the absence of lubricant, the interactions between the TiWCN coating and the workpiece material were considerably less favourable than those of the VCN coating, as revealed by the $38 \%$ greater torque required. Consequently, friction when the TiWCN coated die sheared the reacted layer was less than when it sheared the workpiece, and less again when $\mathrm{MoS}_{2}$ was also present to further impede direct contact. For VCN, more favourable interactions with the workpiece meant that friction increased when it was the reacted layer being sheared. Moreover, it appears that shearing of the AW/EP film was so dominant in terms of torque that the addition of $\mathrm{MoS}_{2}$, which by itself made comparatively small difference, had no discernible effect.

Cylinder upsetting operations revealed significant differences in the performance of boundary regime lubricants at the upper die-workpiece interface during cold rotational rotary forging. 
Although the test method was simpler than that of forming $90^{\circ}$ flange bends on tubular preforms, this is a compromise that is often made for the initial down-selection of lubricants and coatings for a manufacturing process. This notwithstanding, by virtue of involving an actual forging process in a full-scale press, it was possible to achieve reasonably representative contact conditions including continuous creation of nascent workpiece surface. In order to determine whether promising lubricant behaviours are replicated during manufacture of larger, more complex components, further studies analogous to that presented here are required. In this regard, it is pertinent that when a tubular Inconel 718 preform of $6 \mathrm{~mm}$ wall thickness was cold forged into a $90^{\circ}$ flange, workpiece temperatures were comparable to those during this cylinder upsetting operation [7]. Of particular interest are whether the synergism between $\mathrm{MoS}_{2}$ and ashless phosphate esters in mineral oil, and the positive relationship between friction at the upper interface and homogeneity of deformation, continue. If both are revealed to be the case, then it must be ascertained whether benefits are outweighed by any detrimental effect that higher friction may have on die life. Such investigations into long-term performance, however, typically first require industrial implementation of a process in order to generate the necessary data.

\section{Conclusions}

- Two PVD die coatings and five boundary regime lubricants in dispersed form were evaluated for cold rotational rotary forging the high-strength, martensitic aerospace steel Jethete M152. The test method was a cylinder upsetting operation in a full-scale industrial press, and the lubricants were applied via in-process spraying. The tribological interaction investigated was rolling-sliding at the upper die-workpiece interface.

- In the absence of a lubricant, upper die total process torque with a TiWCN PVD coating was almost $40 \%$ greater than with a VCN coating. 
- The level of equivalence between die coating torque-time plots when a lubricant was employed was proposed as an indicator of the completeness of the interfacial barrier generated. Remarkable equivalence was achieved with $\mathrm{ZnS}$ in $\mathrm{H} 2 \mathrm{O}$ once preceding forming cycles in a run had generated a lubricant particle film of sufficient thickness over the forging face. A high level of equivalence occurred for all cycles using microMoS2 and an ashless phosphate ester in mineral oil, and seemingly without any such tribofilm formation.

- For the solid-in-liquid lubricants, friction and surface finish were to a large extent dependent on whether the dispersion medium was water- or oil-based. In the case of the former, dry films were in effect deposited because surface temperatures caused carrier liquid to vaporise. The resultant solid-state coatings more completely obstructed asperity contact, which reduced friction, hindered smoothing and facilitated third-body abrasion.

- A tribological synergism occurred when MoS2 micro-platelets were mixed with an ashless phosphate ester in mineral oil. Components formed using this lubricant did not appear to suffer the abrasion/imprinting or tearing that affected those formed using the lamellar particles or AW/EP additive, respectively, dispersed alone in oil. Further synergistic effects were superior protection against adhesive wear and torque-time plots that were almost independent of die coating identity.

- Higher friction at the upper die-workpiece interface correlated with increased flow at the lower interface and greater homogeneity of through-thickness deformation.

\section{Acknowledgements}

The author would like to acknowledge Rolls-Royce plc for funding this work from their Innovate UK: Aerospace Technology Institute Strategic R\&D Project grant (application no. 
66733-263147) titled "Manufacturing Portfolio Project 2: Manufacture of Advanced

Materials.

Gratitude is expressed to Martin Tuffs and Andrew Walpole at Rolls-Royce plc for their enthusiasm and support; Bhaskaran Krishnamurthy for conversations about the mechanics of rotary forging; and Thomas Hicks and Kyle Watt for operating the press.

\section{References}

[1] Chou ACP, Chou PC, Rogers AC. Rotary Forging. In: Semiatin SL, editor. ASM Handbook, Volume 14A- Metalworking: Bulk Forming. Materials Park, Ohio: ASM International; 2005. p. 179-82.

[2] Krishnamurthy B, Bylya O, Muir L, Conway A, Blackwell P. On the specifics of modelling of rotary forging processes. Computer Methods in Materials Science. 2017;17:229.

[3] Nowak J, Madej L, Ziolkiewicz S, Plewinski A, Grosman F, Pietrzyk M. Recent development in orbital forging technology. International Journal of Material Forming. 2008;1:387-90.

[4] Han X, Hua L. Comparison between cold rotary forging and conventional forging. Journal of Mechanical Science and Technology. 2009;23:2668.

[5] Pérez M. Microstructural and texture evolution of Jethete M152 flanged-test pieces during cold rotary forging. Journal of Materials Processing Technology. 2018;252:582-94.

[6] Pérez M. Analysis of Innovative Incremental Cold Forming Process for the Manufacturing of Aerospace Rotating Parts. Proceedings of the ASME 2017 12th International Manufacturing Science and Engineering Conference. Los Angeles: American Society of Mechanical Engineers; 2017. p. V001T02A56.

[7] Mandal P, Lalvani H, Tuffs M. Cold rotary forging of Inconel 718. Journal of Manufacturing Processes. 2019;46:77-99.

[8] Han X, Hu Y, Hua L. Cold orbital forging of gear rack. International Journal of Mechanical Sciences. 2016;117:227-42.

[9] Han X, Hua L. Prediction of contact pressure, slip distance and wear in cold rotary forging using finite element methods. Tribology International. 2011;44:1742-53.

[10] Han X, Hua L. Friction behaviors in cold rotary forging of 20CrMnTi alloy. Tribology International. 2012;55:29-39.

[11] Han X, Hua L. 3D FE modeling simulation for wear in cold rotary forging of 20CrMnTi alloy. Journal of Tribology. 2013;135:011101.

[12] Deng X, Hua L, Han X, Song Y. Numerical and experimental investigation of cold rotary forging of a 20CrMnTi alloy spur bevel gear. Materials \& Design. 2011;32:1376-89. [13] Jin Q, Gu Z, Hua J. Preform designing approach in cold orbital forging of flange gear. Advances in Mechanical Engineering. 2018;10:1687814018808620.

[14] Han X, Hua L. Effect of size of the cylindrical workpiece on the cold rotary-forging process. Materials \& Design. 2009;30:2802-12.

[15] Pérez M. Impact of annealing treatments on the softening and work hardening behaviour of Jethete M152 alloy for subsequent cold forming processes. Materials Science and Engineering: A. 2017;690:303-12. 
[16] Buchinger J, Koutná N, Chen Z, Zhang Z, Mayrhofer PH, Holec D, et al. Toughness enhancement in TiN/WN superlattice thin films. Acta Materialia. 2019;172:18-29.

[17] Hahn R, Bartosik M, Soler R, Kirchlechner C, Dehm G, Mayrhofer PH. Superlattice effect for enhanced fracture toughness of hard coatings. Scripta Materialia. 2016;124:67-70.

[18] Sangiovanni D, Chirita V, Hultman L. Toughness enhancement in TiAlN-based quarternary alloys. Thin Solid Films. 2012;520:4080-8.

[19] Tomala A, Ripoll MR, Gabler C, Remškar M, Kalin M. Interactions between MoS2 nanotubes and conventional additives in model oils. Tribology International. 2017;110:14050 .

[20] Tomala A, Ripoll MR, Kogovšek J, Kalin M, Bednarska A, Michalczewski R, et al. Synergisms and antagonisms between MoS2 nanotubes and representative oil additives under various contact conditions. Tribology International. 2019;129:137-50.

[21] Tomala A, Vengudusamy B, Ripoll MR, Suarez AN, Remškar M, Rosentsveig R. Interaction between selected MoS 2 nanoparticles and ZDDP tribofilms. Tribology letters. 2015;59:26.

[22] Chhowalla M, Shin HS, Eda G, Li L-J, Loh KP, Zhang H. The chemistry of twodimensional layered transition metal dichalcogenide nanosheets. Nature Chemistry. 2013;5:263-75.

[23] Lince JR, Carré DJ, Fleischauer PD. Schottky-barrier formation on a covalent semiconductor without Fermi-level pinning: The metal-\$ $\{\backslash$ mathrm $\{\operatorname{MoS}\}\} \_\{2\} \$(0001)$ interface. Physical Review B. 1987;36:1647-56.

[24] Costello S, McCracken S. Perfect Edge 3D ${ }^{\mathrm{TM}}$ : Enabling Root-Cause Failure Analysis. 47th International Symposium on Microelectronics: Future of Packaging. San Diego: International Microelectronics Assembly and Packaging Society; 2014. p. 647-52. [25] Podgornik B, Kafexhiu F, Kosec T, Jerina J, Kalin M. Friction and anti-galling properties of hexagonal boron nitride (h-BN) in aluminium forming. Wear. 2017;388:2-8. [26] Ljungcrantz H, Hultman L, Sundgren JE, Håkansson G, Karlsson L. Microstructural investigation of droplets in arc-evaporated TiN films. Surface and Coatings Technology. 1994;63:123-8.

[27] Münz WD, Lewis DB, Creasey S, Hurkmans T, Trinh T, Ijzendorn W. Defects in TiN and TiAIN coatings grown by combined cathodic arc/unbalanced magnetron technology. Vacuum. 1995;46:323-30.

[28] Bull S, Bhat D, Staia M. Properties and performance of commercial TiCN coatings. Part 2: tribological performance. Surface and Coatings Technology. 2003;163:507-14.

[29] Tkadletz M, Mitterer C, Sartory B, Letofsky-Papst I, Czettl C, Michotte C. The effect of droplets in arc evaporated TiAlTaN hard coatings on the wear behavior. Surface and Coatings Technology. 2014;257:95-101.

[30] Decheng Z, Shijian Y, Wang Z, Zhenrui X. Defects caused in forming process of rotary forged parts and their preventive methods. Journal of Materials Processing Technology. 1992;32:471-9.

[31] Liu G, Yuan S, Wang Z, Zhou D. Explanation of the mushroom effect in the rotary forging of a cylinder. Journal of Materials Processing Technology. 2004;151:178-82.

[32] Cho D-H, Kim J-S, Kwon S-H, Lee C, Lee Y-Z. Evaluation of hexagonal boron nitride nano-sheets as a lubricant additive in water. Wear. 2013;302:981-6.

[33] Mosleh M, Atnafu ND, Belk JH, Nobles OM. Modification of sheet metal forming fluids with dispersed nanoparticles for improved lubrication. Wear. 2009;267:1220-5.

[34] Reeves CJ, Menezes PL, Lovell MR, Jen T-C. The size effect of boron nitride particles on the tribological performance of biolubricants for energy conservation and sustainability. Tribology Letters. 2013;51:437-52. 
[35] Bart JCJ, Gucciardi E, Cavallaro S. Biolubricants: science and technology. 1st ed. Cambridge: Woodhead Publishing Limited; 2013.

[36] Kang J-j, Wang C-b, Wang H-d, Xu B-s, Liu J-j, Li G-l. Research on tribological behaviors of composite $\mathrm{Zn} / \mathrm{ZnS}$ coating under dry condition. Applied Surface Science. 2012;258:1940-3.

[37] Phillips DW. Ashless phosphorus-containing lubricating oil additives. In: Rudnick L, editor. Lubricant Additives-Chemistry and Applications. 2nd ed. Boca Raton, Florida: CRC Press; 2009. p. 63-121.

[38] Johnson D, Hils J. Phosphate esters, thiophosphate esters and metal thiophosphates as lubricant additives. Lubricants. 2013;1:132-48.

[39] Lubbinge H, Haar Rt, Schipper DJ. The Influence of Plastic Bulk Deformation on Surface Roughness and Frictional Behavior during Deep Drawing Processes. Proceedings of the 22nd Leeds-Lyon Symposium on Tribology. Lyon: Elsevier; 1996. p. 705-11.

[40] Wilson WR, Lee W. Mechanics of surface roughening in metal forming processes. Journal of manufacturing science and engineering. 2001;123:279-83.

[41] Lansdown AR. Molybdenum disulphide lubrication. 1st ed. Amsterdam: Elsevier; 1999. [42] Lancaster J. Anisotropy in the mechanical properties of lamellar solids and its effect on wear and transfer. Wear. 1966;9:169-88.

[43] Buchner B, Maderthoner G, Buchmayr B. Characterisation of different lubricants concerning the friction coefficient in forging of AA2618. Journal of materials processing technology. 2008;198:41-7.

[44] Groche P, Müller C, Jahn A. Effects of the tool lubrication in cold forging. Tribology Letters. 2014;53:599-605.

[45] Krajewski PE, Morales AT. Tribological issues during quick plastic forming. Journal of materials engineering and performance. 2004;13:700-9.

[46] Aldana PU, Vacher B, Le Mogne T, Belin M, Thiebaut B, Dassenoy F. Action

Mechanism of WS2 Nanoparticles with ZDDP Additive in Boundary Lubrication Regime.

Tribology Letters. 2014;56:249-58.

[47] Gänsheimer J. Influence of Certain Vapors and Liquids on the Frictional Properties of Molybdenum Disulfide. A S L E Transactions. 1967;10:390-9.

[48] Papay A. Antiwear and extreme- pressure additives in lubricants. Lubrication Science. 1998;10:209-24. 
(a) Oxbital rotary forging

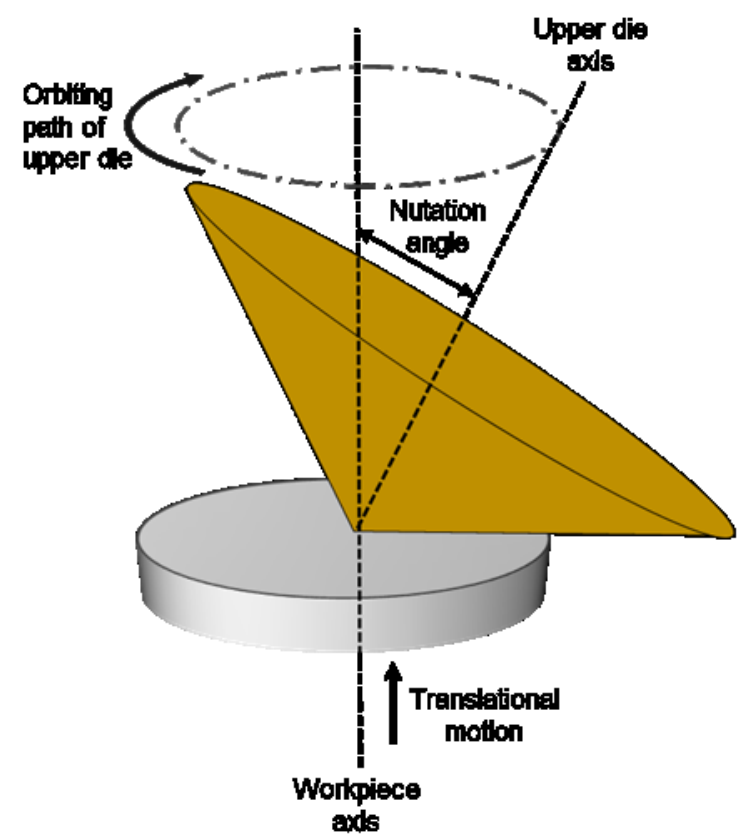

(b) Rotational rotary forging

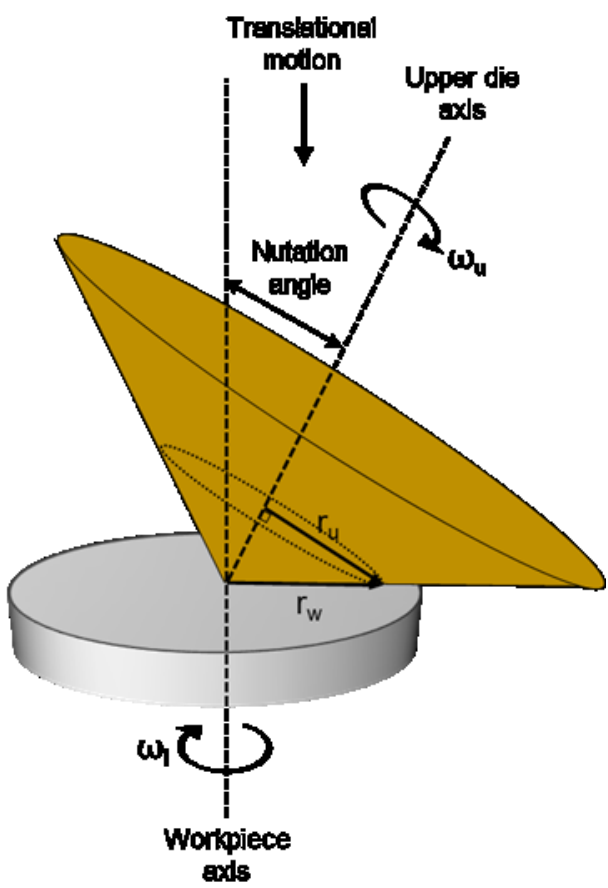

Figure 1 Kinematic scheme of the (a) orbital rotary forging process (the most prevalent variant is shown), and (b) rotational rotary forging process. Annotated symbols in (b) relate to Equation (1). 

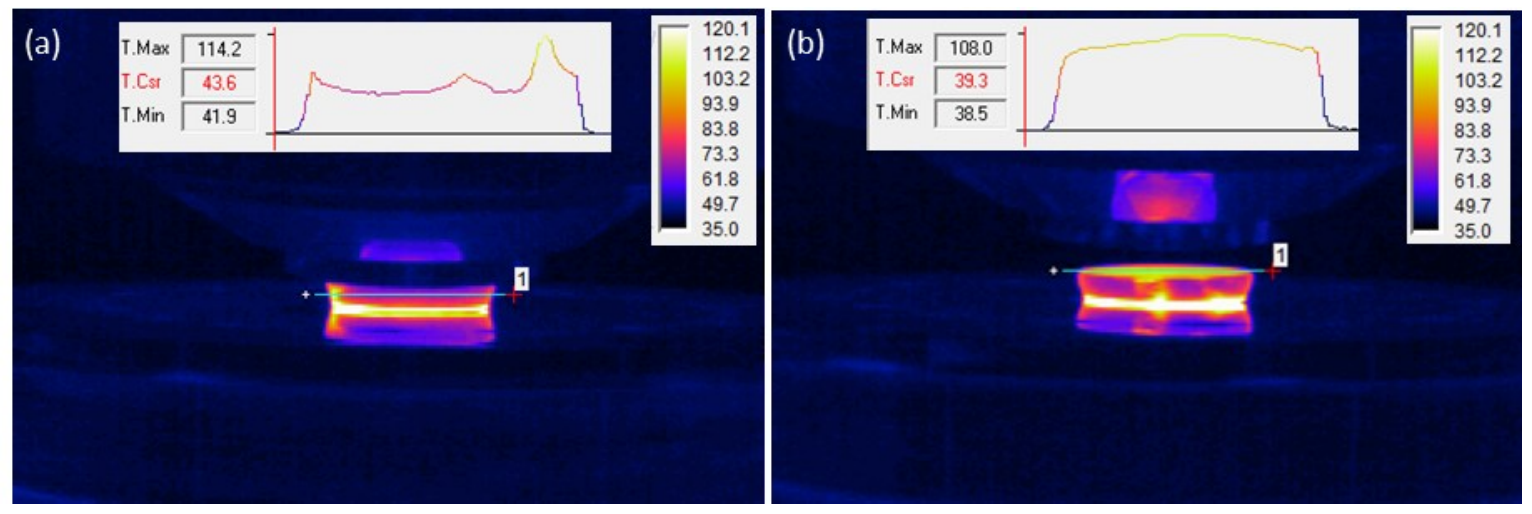

Figure 2 Thermal camera images from the forming cycle using the VCN coated die and no lubricant:

(a) intra-cycle, showing the temperature profile across the lateral workpiece surface; (b) immediately after forging, at the point the die was sufficiently raised to enable the temperature profile across the workpiece upper surface to be captured. 

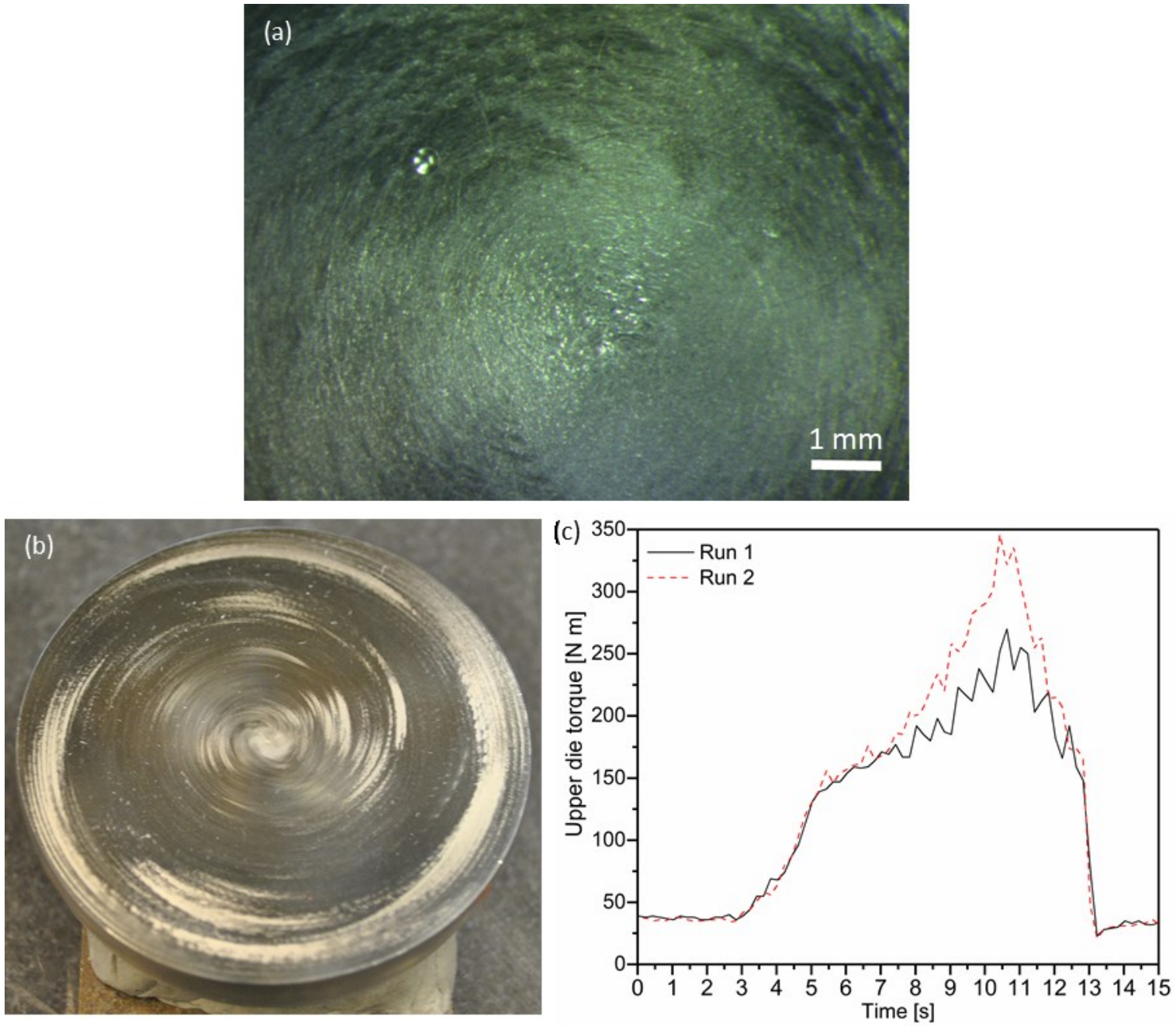

Figure 3 (a) Optical micrograph showing the apex region of an uncoated upper die subsequent to forming a single workpiece in the absence of a lubricant; (b) photograph of the upper surface of a subsequent part formed under these conditions (diameter $\approx 68 \mathrm{~mm}$ ); (c) upper die torque-time plots from the two forming cycles. 


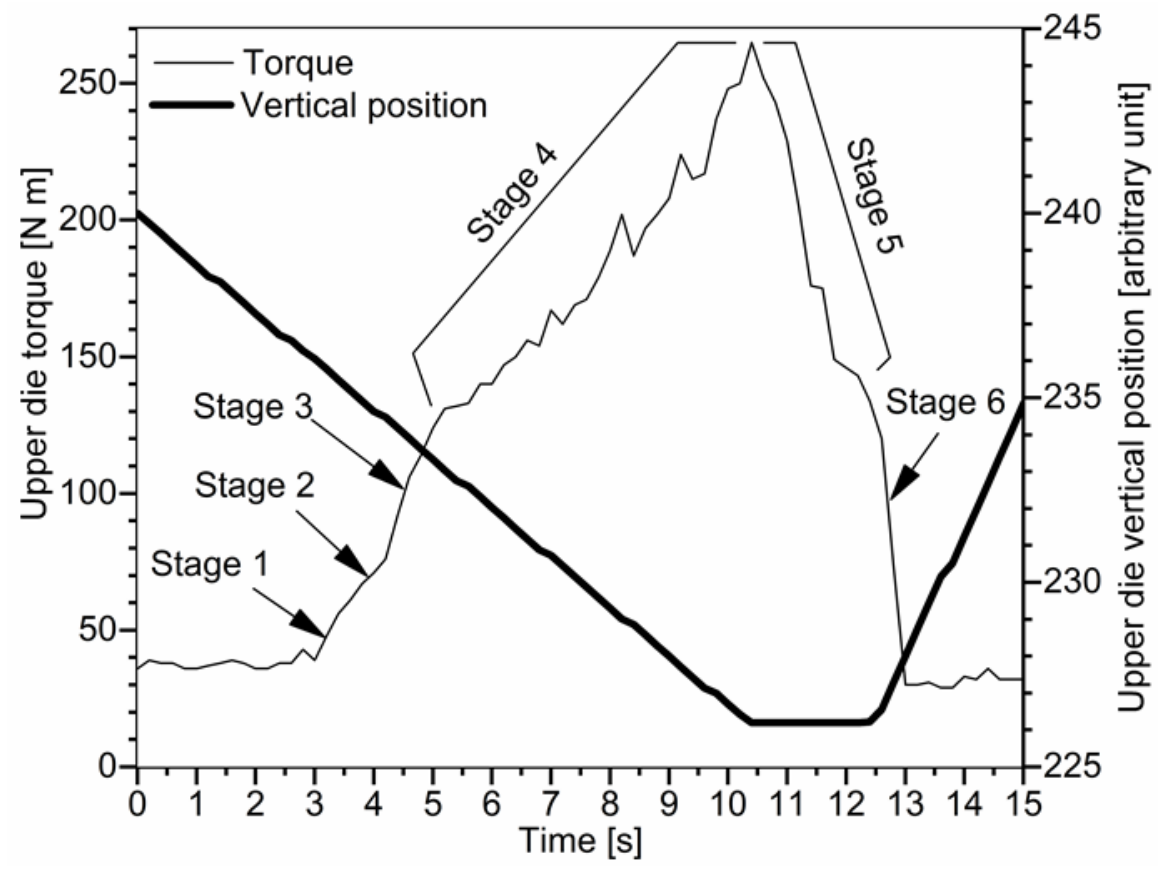

Figure 4 Upper die torque-time plot with the various stages of the forming cycle highlighted. The stages are described in the text. The vertical position of the die is also shown. 

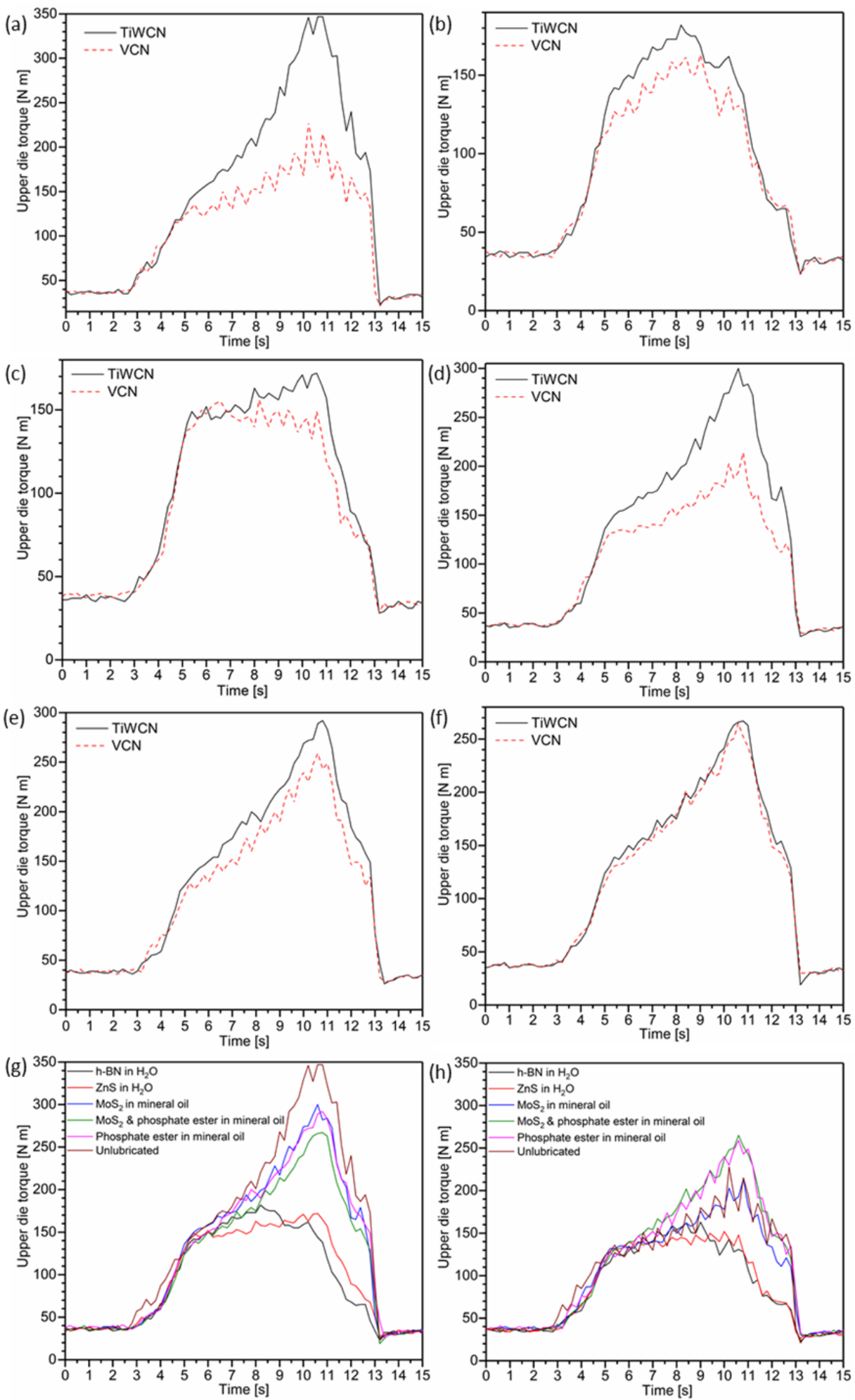

Figure 5 Upper die torque-time plots from all die coating/lubricant combinations: (a) no lubricant, (b) h-BN in $\mathrm{H}_{2} \mathrm{O}$, (c) $\mathrm{ZnS}$ in $\mathrm{H}_{2} \mathrm{O}$, (d) $\mathrm{MoS}_{2}$ in mineral oil, (e) phosphate ester in mineral oil, (f) $\mathrm{MoS}_{2}$ and phosphate ester in mineral oil, (g) all TiWCN single cycles, (h) all VCN single cycles. 

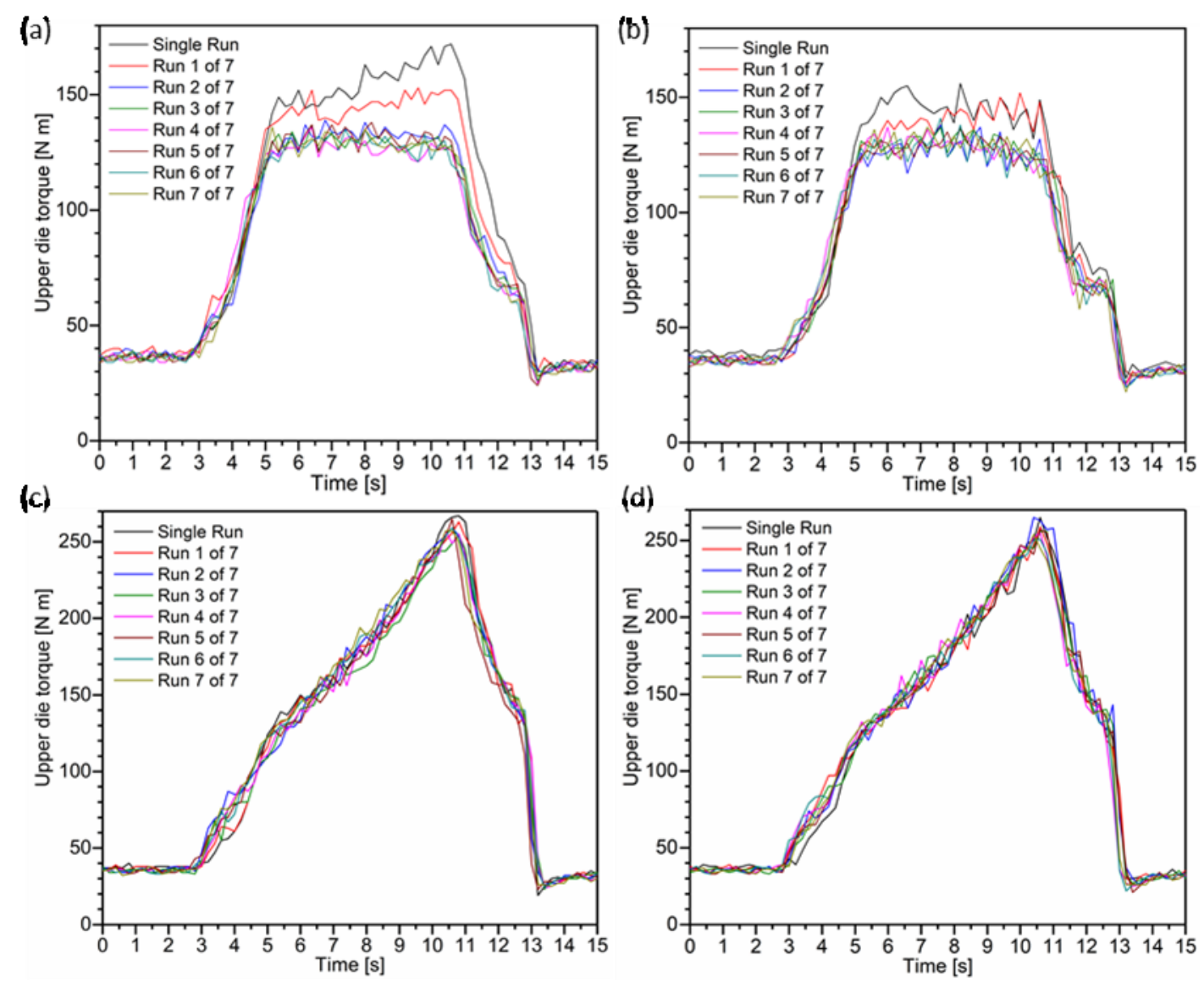

Figure 6 Upper die torque-time plots from the small-batch runs of seven consecutive parts using (a) $\mathrm{ZnS}$ in $\mathrm{H}_{2} \mathrm{O}$ /TiWCN coating, (b) $\mathrm{ZnS}$ in $\mathrm{H}_{2} \mathrm{O} / \mathrm{VCN}$ coating, (c) $\mathrm{MoS}_{2}$ and phosphate ester in mineral oil/TiWCN coating, (d) $\mathrm{MoS}_{2}$ and phosphate ester in mineral oil/VCN coating. Each figure also contains the plot from the initial single cycle. 


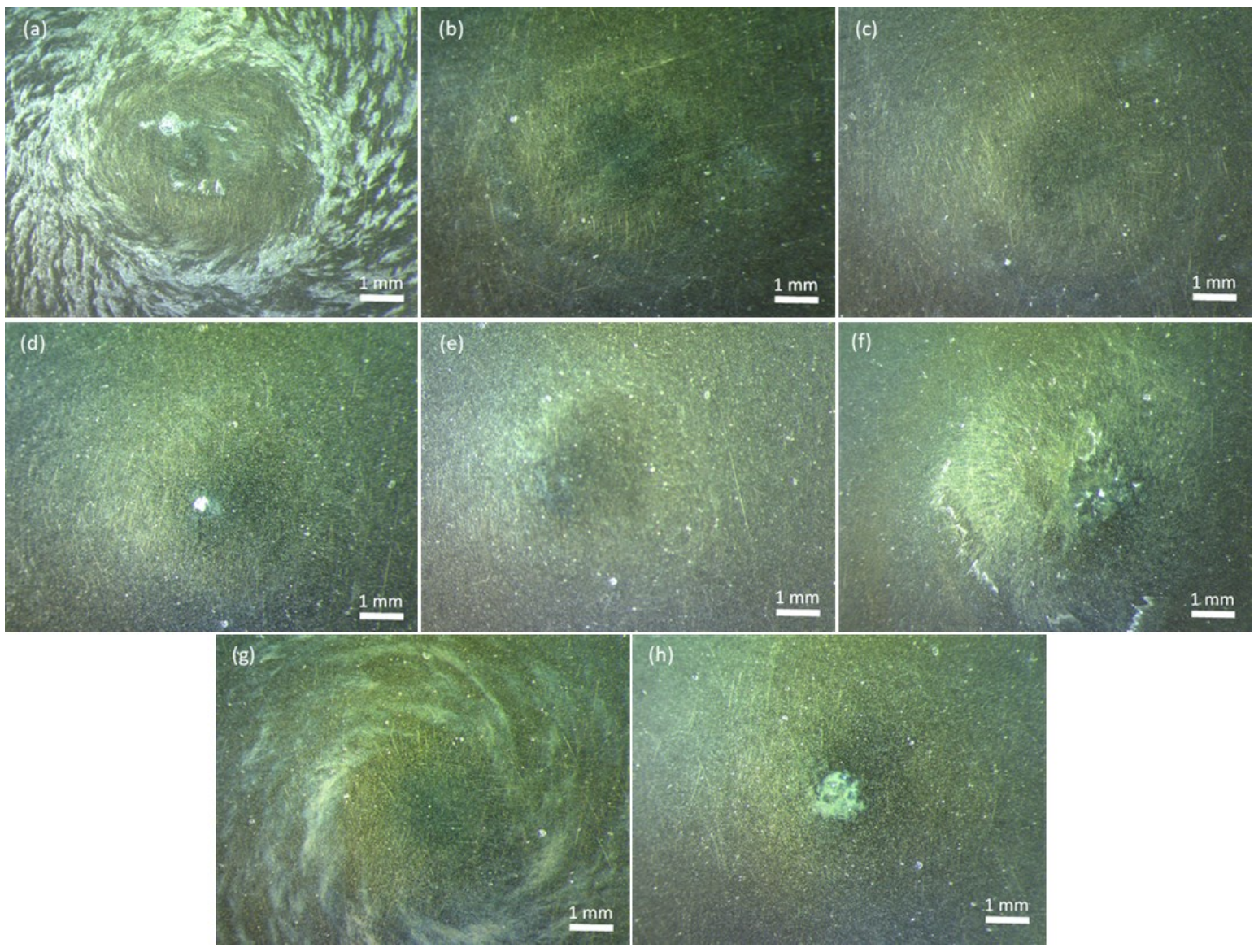

Figure 7 Optical micrographs showing the apex region of the VCN coated die after single cycles: (a) h-BN in $\mathrm{H}_{2} \mathrm{O}$, (b) $\mathrm{ZnS}$ in $\mathrm{H}_{2} \mathrm{O}$, (c) $\mathrm{MoS}_{2}$ in mineral oil, (d) phosphate ester in mineral oil, (e) $\mathrm{MoS}_{2}$ and phosphate ester in mineral oil, (f) no lubricant; and after seven consecutive cycles: (g) ZnS in $\mathrm{H}_{2} \mathrm{O}$, (h) $\mathrm{MoS}_{2}$ and phosphate ester in mineral oil. 


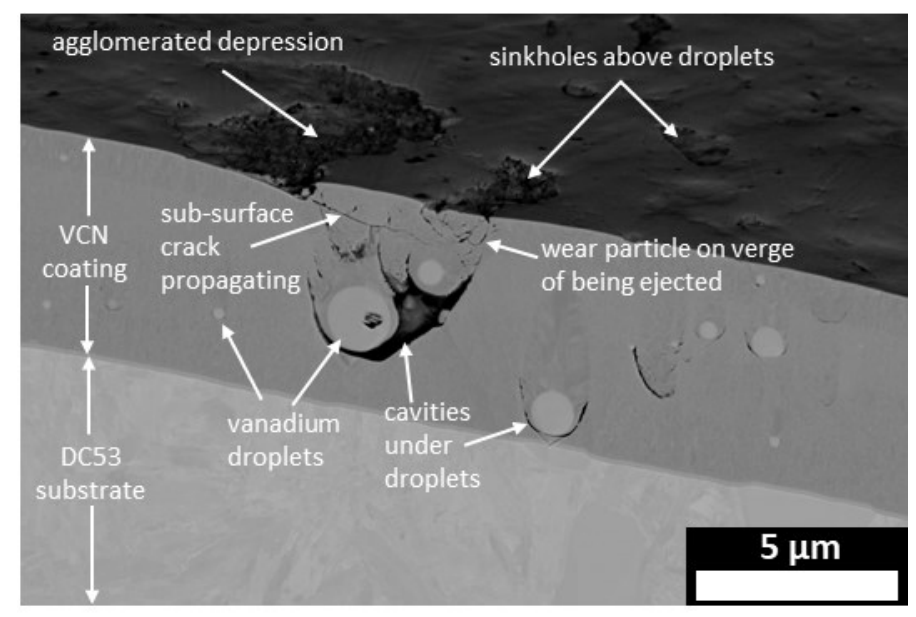

Figure 8 SEM micrograph showing the combined surface and cross-section of the VCN die coating in the vicinity of depressions that formed over the course of the experiments. 


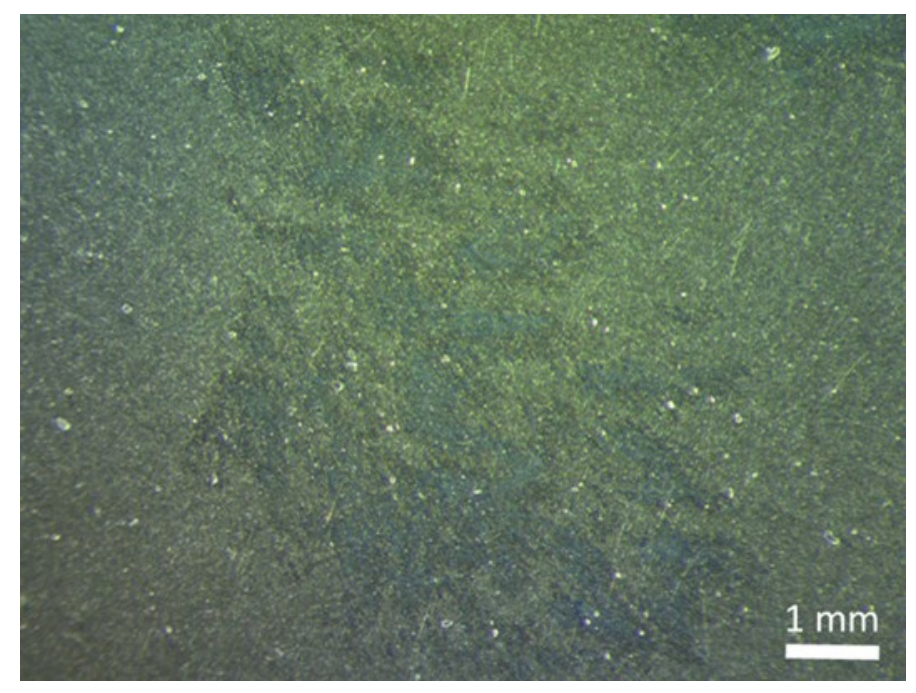

Figure 9 Optical micrograph showing a region of damage sustained by the VCN die coating during a single unlubricated forming cycle. The TiWCN coating was affected similarly. 


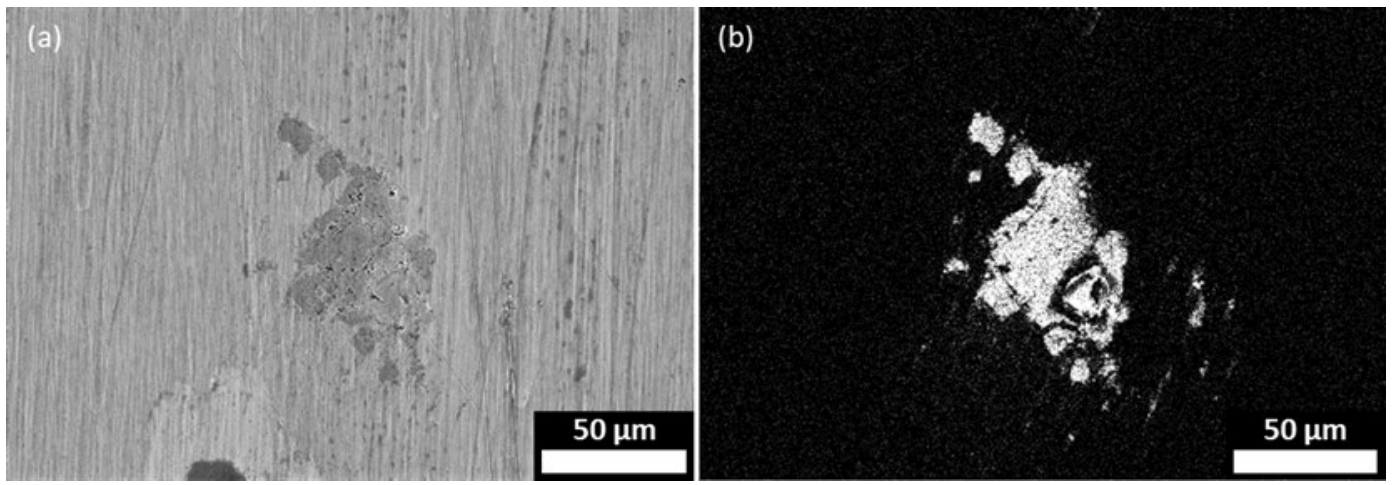

Figure 10 (a) SEM secondary electron image and (b) titanium EDS map showing a transfer patch from the TiWCN die coating. 


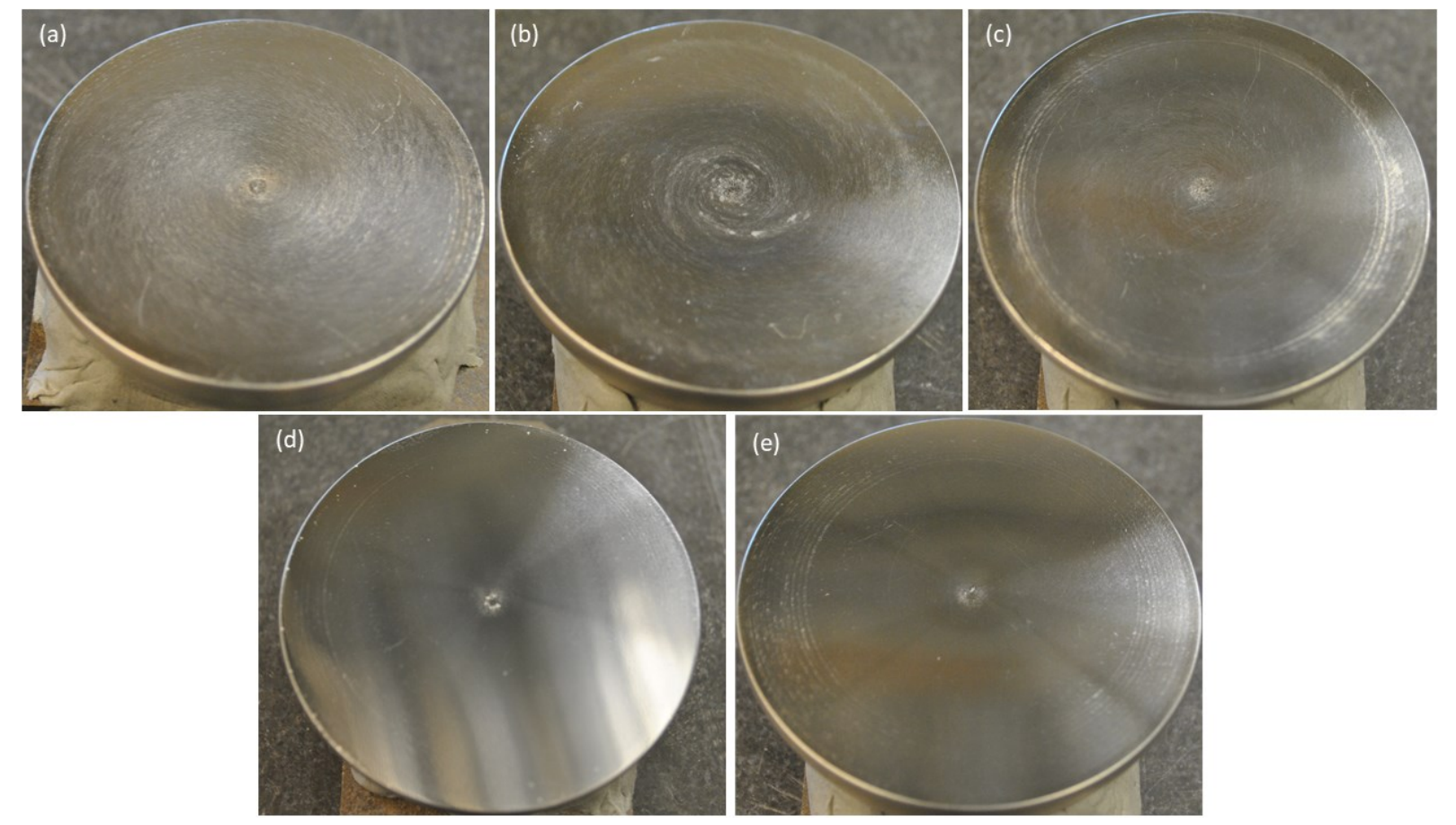

Figure 11 Photographs showing the upper surface of workpieces formed using the VCN coated die and (a) h-BN in $\mathrm{H}_{2} \mathrm{O}$, (b) $\mathrm{ZnS}$ in $\mathrm{H}_{2} \mathrm{O}$, (c) $\mathrm{MoS}_{2}$ in mineral oil, (d) phosphate ester in mineral oil, and (e) $\mathrm{MoS}_{2} /$ phosphate ester in mineral oil. The diameter of each was approximately $68 \mathrm{~mm}$. The upper surfaces of the corresponding workpieces formed using the TiWCN coated die were equivalent. 


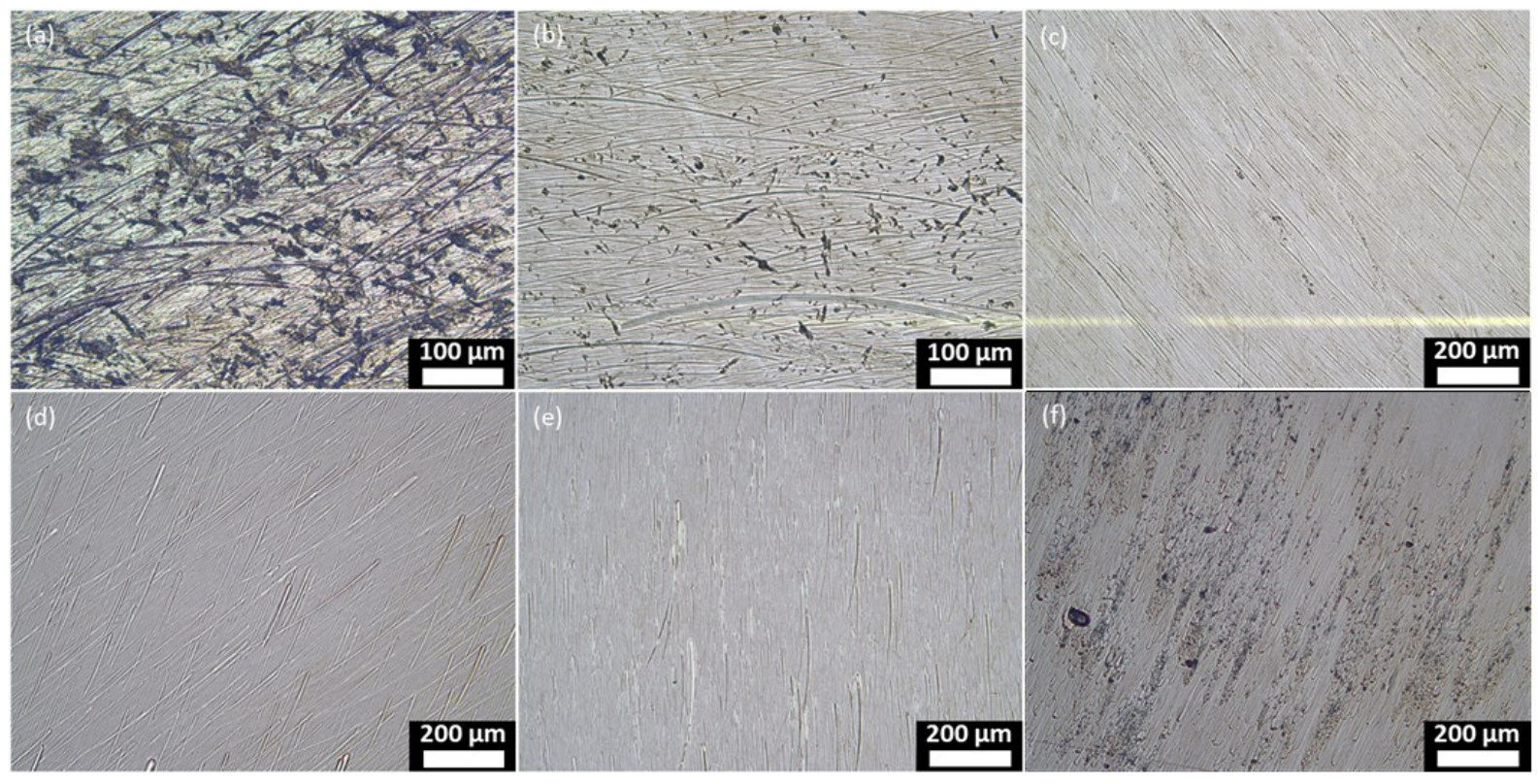

Figure 12 Optical micrographs showing typical regions of the upper surface of workpieces formed using the VCN coated die and (a) h-BN in $\mathrm{H}_{2} \mathrm{O}$, (b) $\mathrm{ZnS}$ in $\mathrm{H}_{2} \mathrm{O}$, (c) $\mathrm{MoS}_{2}$ in mineral oil, (d) phosphate ester in mineral oil, and (e) $\mathrm{MoS}_{2} /$ phosphate ester in mineral oil, (f) shows a region of dark marks that occurred in the absence of a lubricant. The upper surfaces of the corresponding workpieces formed using the TiWCN coated die were equivalent. 

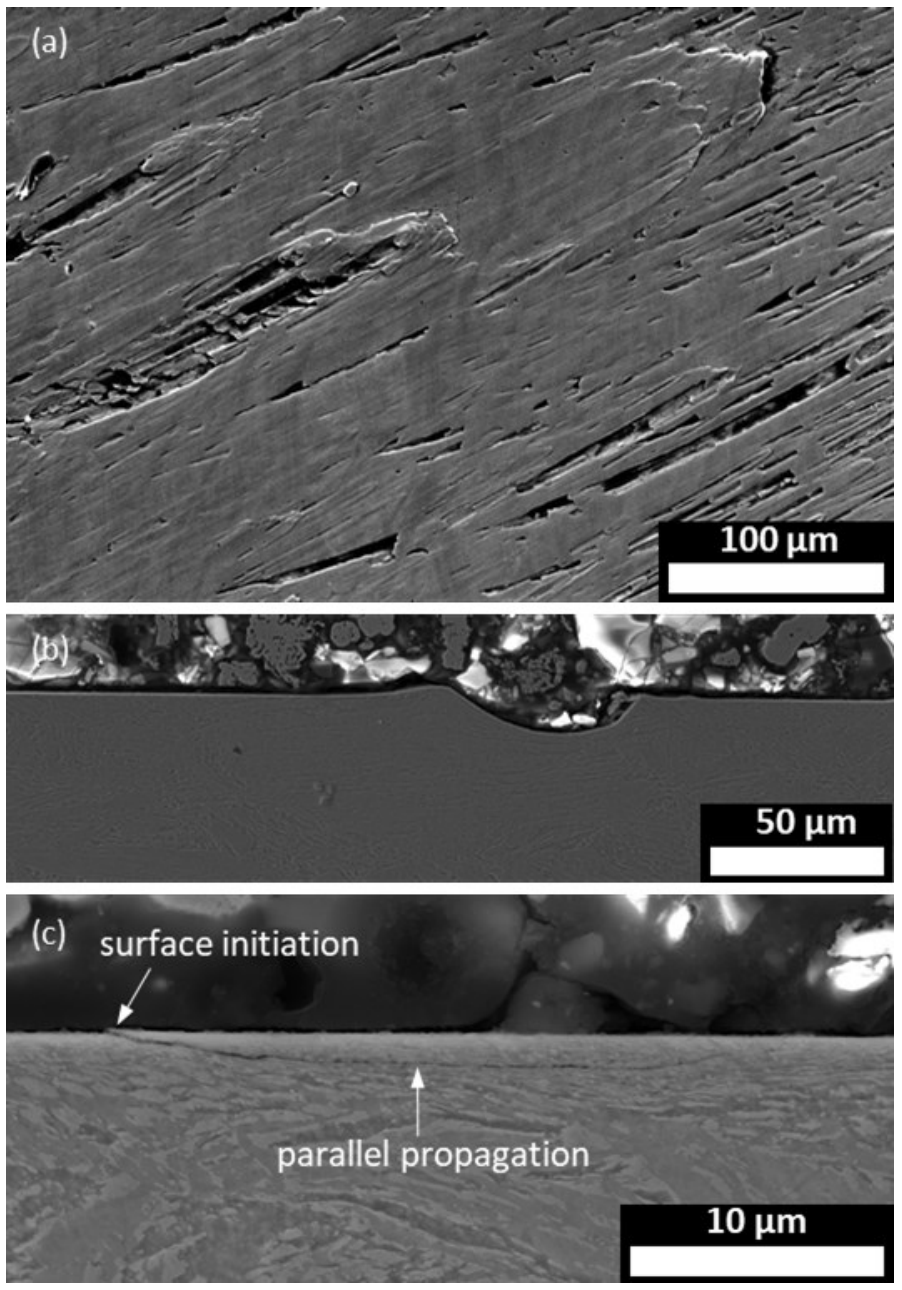

Figure 13 SEM secondary electron images from the workpiece formed using the VCN coated die and no lubricant. Surface grooves as viewed from (a) top-down and (b) cross-section; (c) cross-section image showing a sub-surface crack. The upper region of (b) and (c) is mounting resin. 


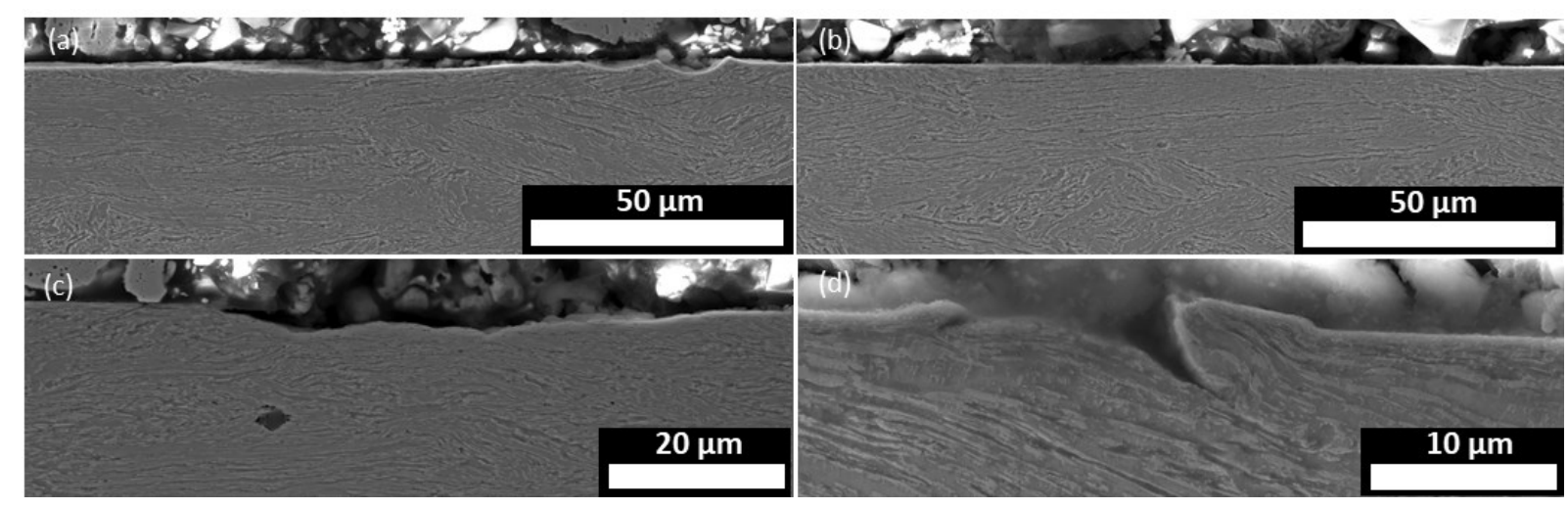

Figure 14 SEM secondary electron images showing the typical near-surface region of workpieces formed using: (a) $\mathrm{ZnS}$ in $\mathrm{H}_{2} \mathrm{O}$, and (b) $\mathrm{MoS}_{2}$ in mineral oil, phosphate ester in mineral oil and $\mathrm{MoS}_{2} /$ phosphate ester in mineral oil. Examples of: (c) sporadic depressions when using $\mathrm{MoS}_{2}$ in mineral oil, and (d) off-vertical cracks when using phosphate ester in mineral oil. The upper region of each micrograph is mounting resin. 
(a)

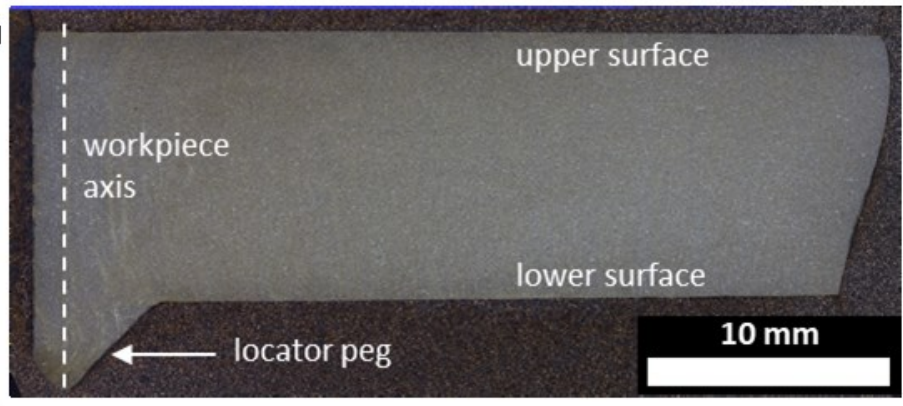

(b)

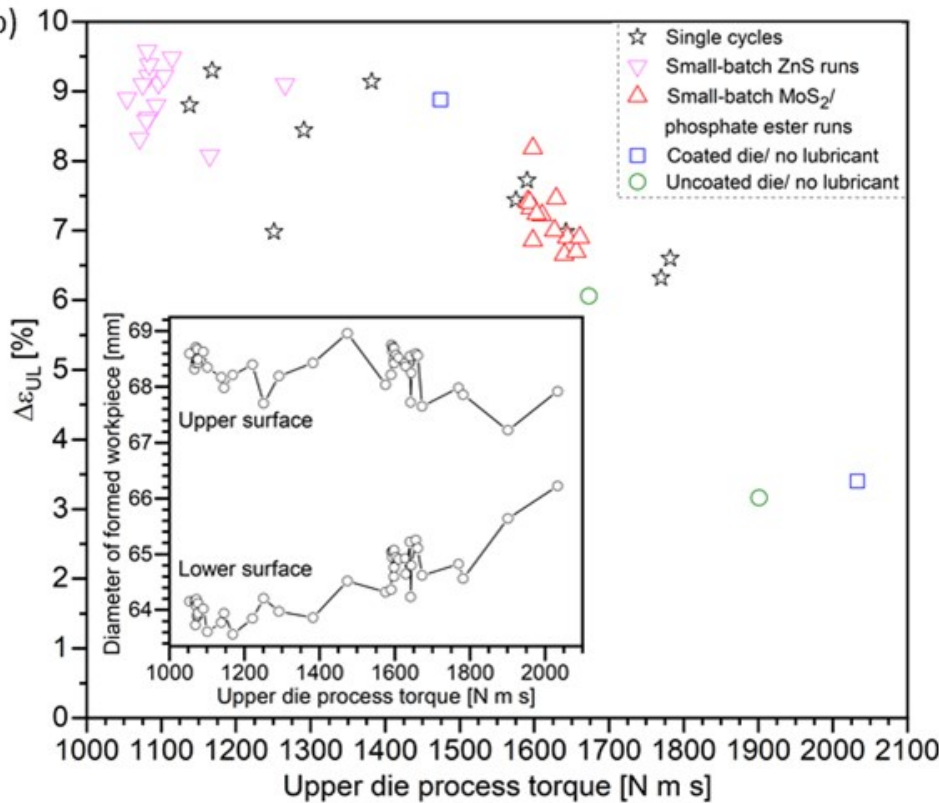

Figure 15 (a) Optical microscope image of a cross-sectioned workpiece. That shown was formed using the VCN coated die and $\mathrm{MoS}_{2} /$ phosphate ester in mineral oil. (b) Plot illustrating how the extent of the "mushroom effect" changed with upper die process torque. Inset shows the variation of workpiece upper and lower diameters with torque. 